\title{
The Modulation of Interdecadal Pacific Oscillation and Atlantic Multidecadal Oscillation on winter Eurasian Cold Anomaly via the Ural Blocking Change
}

\section{Binhe Luo}

Ocean University of China - Laoshan Campus: Ocean University of China

Dehai Luo ( $\sim$ ldh@mail.iap.ac.cn )

RCE-TEA, Institute of Atmospheric Physics, Chinese Academy of Science

Aiguo Dai

University at Albany State University of New York

Simmonds lan

The University of Melbourne

\section{Lixin Wu}

Ocean University of China - Laoshan Campus: Ocean University of China

\section{Research Article}

Keywords: Eurasian cold anomaly (ECA) , Modulation , Interdecadal Pacific Oscillation, Atlantic Multidecadal Oscillation, Ural Blocking Change

Posted Date: May 6th, 2021

DOI: https://doi.org/10.21203/rs.3.rs-437125/v1

License: (c) (i) This work is licensed under a Creative Commons Attribution 4.0 International License.

Read Full License

Version of Record: A version of this preprint was published at Climate Dynamics on January 5th, 2022. See the published version at https://doi.org/10.1007/s00382-021-06119-7. 


\title{
The modulation of Interdecadal Pacific Oscillation and Atlantic
}

\section{Ural blocking change Multidecadal Oscillation on winter Eurasian cold anomaly via the}

\author{
Binhe Luo ${ }^{\mathrm{a}, \mathrm{b})}$, Dehai Luo ${ }^{\mathrm{b})}$, Aiguo Dai ${ }^{\mathrm{c})}$, Ian, Simmonds ${ }^{\mathrm{d})}$ and Lixin $\mathrm{Wu}^{\mathrm{a})}$
}

(a) Key Laboratory of Physical Oceanography/Institute for Advanced Ocean Studies, Ocean University of China and Qingdao National Laboratory for Marine Science and Technology, Qingdao, China

(b) Key Laboratory of Regional Climate-Environment for Temperate East Asia, Institute of Atmospheric Physics, Chinese Academy of Sciences, Beijing, China, 100029 and University of Chinese Academy of Sciences, Beijing, China

(c) Department of Atmospheric and Environmental Sciences, University at Albany, SUNY, Albany, NY 12222, USA

(d) School of Earth Sciences, The University of Melbourne, Victoria, Australia Submitted to Climate Dynamics

Date: 16 April, 2021

Corresponding author address: Dr. Dehai Luo, Institute of Atmospheric Physics, Chinese Academy of Science, Beijing, 100029, Email: 1dh@mail.iap.ac.cn 
Abstract

Observations revealed distinct interdecadal winter Eurasian cold anomaly (ECA) centered

over central Eurasia $\left(40^{\circ}-60^{\circ} \mathrm{N}, 60^{\circ}-120^{\circ} \mathrm{E}\right)$, with a more southwestward extension during

1965-1976 than during 2002-2013. In this paper, Ural blockings (UB) in association with the

Interdecadal Pacific Oscillation (IPO) and Atlantic Multi-decadal Oscillation (AMO) are

analyzed to explain the ECA's interdecadal change using reanalysis data. It is found that the

1965-1976 winter ECA is associated with the negative-phase IPO (IPO-) together with

negative-phase AMO (AMO-), while the 2002-2013 ECA is related to positive-phase AMO

$\left(\mathrm{AMO}^{+}\right)$concurring with IPO-

The UB mainly related to positive North Atlantic Oscillation is long-lived during IPO- $^{-}$and $\mathrm{AMO}^{+}$and shows different longitudinal position and movement, but short-lived and retrograde during both $\mathrm{IPO}^{+}$and $\mathrm{AMO}^{-}$. During $\mathrm{IPO}^{-}$, the UB grows rapidly and decays slowly due to weak westerly winds and small meridional potential vorticity gradient $\left(\mathrm{PV}_{\mathrm{y}}\right)$ over North Atlantic mid-high latitudes, and moves westward mainly during its decay stage, causing strong cold anomalies over central Eurasia and its upstream region $\left(30^{\circ}-50^{\circ} \mathrm{N}, 30^{\circ}-70^{\circ} \mathrm{E}\right)$. Such a slow blocking decay is also seen during $\mathrm{AMO}^{-}$. However, during $\mathrm{AMO}^{+}$the $\mathrm{UB}$ grows slowly, decays rapidly and shows eastward movement due to strong westerly winds and large $\mathrm{PV}_{\mathrm{y}}$ over

41 North Atlantic high latitudes, causing strong cold anomalies over central Eurasia and its downstream region $\left(30^{\circ}-50^{\circ} \mathrm{N}, 90^{\circ}-130^{\circ} \mathrm{E}\right)$. Through these UB-induced sub-seasonal changes,

43 the interdecadal $\mathrm{IPO}^{-}, \mathrm{AMO}^{-}$and $\mathrm{AMO}^{+}$help explain the variation of the winter-mean $\mathrm{ECA}$ from 1965-1976 to 2002-2013. 


\section{Introduction}

Earth's warming rate slowed down noticeably during 2000-2013, which is often referred to as the recent global warming hiatus (Kaufmann et al. 2011; Karl et al. 2015). The physical cause of the global warming hiatus has been a focus of climate research in recent years (Trenberth and Fasullo, 2013; Kosaka and Xie 2013; Chen and Tung, 2014; Trenberth, 2015; Marotzke and Forster 2015; Wei et al. 2015; Meehl et al. 2016; Huang et al. 2017). Many studies have revealed that the recent warming hiatus was mainly caused by internal multi-decadal variability in Pacific and Atlantic sea surface temperatures (SSTs), primarily associated with the Interdecadal Pacific Oscillation (IPO) (Meehl et al. 2013, 2016; Dai et al. 2015) and the Atlantic Multidecadal Oscillation (AMO) (Dai et al. 2015; Steinman et al. 2015). Furthermore, some studies indicated that the hiatus was associated with the anomalously cold surface air temperatures over Eurasia seen mainly in winter (Cohen et al. 2012; Li et al. 2015; Luo et al. 2016; Yao et al. 2017; Huang et al. 2017; Deser et al. 2017). In particular, Deser et al. (2017) found that the Eurasian cold anomaly (ECA) may account for $71 \%$ of the recent slowdown in winter global warming rate during 2000-2013. The winter ECA also occurred during 1965-1976 (Wei et al. 2015; Huang et al. 2017), and the winter ECA's interdecadal variation is found to be associated with the North Atlantic interdecadal variability (Sung et al. 2018). Thus, it is likely that the IPO and AMO may have contributed to the decadal winter ECAs, including the recent warming hiatus.

Previous studies have established a connection between the interdecadal variability of Northern Hemisphere $(\mathrm{NH})$ or global winter air temperatures and the IPO and AMO from the 
statistical and dynamical perspectives (Wyatt et al. 2012; Dai et al. 2015; Steinman et al. 2015;

Dong and Dai 2015; Sung et al. 2018). However, it is unclear how and whether the IPO and AMO could influence winter ECA through their modulation of the Ural blocking (UB), a blocking anticyclone over the Ural Mountains around $60^{\circ} \mathrm{E}$ and $50^{\circ}-70^{\circ} \mathrm{N}$ on a timescale of 10-20 days, as the winter ECA is closely related to the presence of UB (Luo et al. 2016a-b; Yao et al. 2017). In particular, we do not know why the spatial distribution of the winter ECA exhibits a large change from 1965-1976 to 2002-2013, and whether and how the spatial pattern of the winter ECA depends on the phases of AMO and IPO or their combinations. While the UB frequency is linked to sea ice loss in Barents-Kara Seas (BKS) (Mori et al. 2014; Luo et al. 2017a; Li et al. 2021), the warm Arctic-cold Siberia (WACS) pattern in winter is associated with the presence of UB (Luo et al. 2016a) and its trend during 1990-2014 is related to increased UB frequency (Mori et al. 2014; Tyrlis et al. 2020; Kim et al. 2021). However, UB's longitudinal location, movement and persistence are more important for the occurrence region and strength of the sub-seasonal ECA over central Eurasia than the strength of blocking itself (Yao et al. 2017). In contrast, the European blocking and Atlantic blocking are not important for the cold anomaly over central Eurasia (B. Luo et al. 2019), while the interdecadal variability of Euro-Atlantic blocking is also related to AMO (Rimbu et al. 2014). Furthermore, Luo et al. (2017b) linked the spatial shape of UB to the AMO. As the winter-mean ECA is derived from the sub-seasonal ECA, we hypothesize that the UB-induced changes in sub-seasonal ECAs may play an important role in causing the recent winter decadal ECA. Nevertheless, what causes the UB in its position, movement and evolution and the sub-seasonal 
87 ECA to vary on decadal time scale is unclear. In particular, the different roles of the IPO and

88 AMO in causing the decadal variations in the UBs and associated sub-seasonal cold anomalies

89 over central Eurasia have not been examined.

90 While Luo et al. (2017b) found that a positive AMO phase $\left(\mathrm{AMO}^{+}\right)$favors persistent

91 northwest-southeast-oriented UB patterns that enhance the sub-seasonal ECAs, they did not

92 explain why a winter ECA occurred during 1965-1976 and had a large difference from the

93 2002-2013 ECA. Moreover, how UB's position, movement and evolution (i.e., growth and

94 decay) change with the IPO and AMO, and how such UB changes influence the sub-seasonal

95 ECA are not explored in Luo et al. (2017b) or any other studies. Here, we investigate the

96 different behavior of the UB under different phases of IPO or AMO and offer a synoptic

97 explanation from a blocking perspective for why the spatial pattern of the winter ECA shows a

98 distinct change from $1965-1976$ to $2002-2013$. We refer to this winter ECA change from

99 1965-1976 to 2002-2013 as the decadal change of ECA in this paper. Because the IPO and

100 AMO are multidecadal modes, they do not directly excite UB events which have a sub-seasonal

101 time scale of 10-20 days. Instead, it can induce interdecadal temperature anomalies and the

102 change in atmospheric background condition and then influence the UB. Thus, we hypothesize

103 that the phase of IPO or AMO can contribute to the change of the winter ECA from 1965-1976

104 to 2002-2013 through interdecadal temperature anomalies and their interdecadal modulation of

105 UB's position, movement, evolution and persistence. We are particularly interested to

106 investigate whether there are different behaviors of the UBs associated with IPO and AMO,

107 and their different modulations of the UB and the associated sub-seasonal ECA. It appears that 
108 the role of the UB's interdecadal change induced by IPO and AMO in the winter ECA change

109 is more important than interdecadal cold anomalies associated with IPO and AMO themselves.

110 These results help explain the change in the spatial pattern of the winter ECA from 1965-1976

111 to 2002-2013, which are not reported in previous studies (e.g., Luo et al. 2017; Sung et al. 2018;

112 B. Luo et al. 2019).

113 This paper is organized as follows: In section 2, we describe the data and method. Section

1143 describes the connections of the ECA during 1965-1976 and 2002-2013 to changes in the UB

115 events. In section 4, we examine how the phase of IPO or AMO modulates the sub-seasonal

116 ECA through changing the position, movement, persistence and evolution of UB events.

117 Section 5 examines the physical processes through which the IPO or AMO modulates the UBs.

118 A summary and conclusions are presented in section 6.

\section{2.Data and method}

120 We used the daily data on a $2.5^{\circ} \times 2.5^{\circ}$ grid for winter (December, January and February,

121 DJF) during the period from December 1950/February 1951 to December 2017/February 2018

122 (1950-2017, hereafter) taken from National Centers for Environmental Prediction-National

123 Center for Atmospheric Research (NCEP-NCAR) reanalysis (Kalnay et al. 1996). They include

124 sea level pressure (SLP), surface air temperature (SAT), 500-hPa geopotential height (Z500)

125 and zonal wind (U500). All the daily data were converted into anomalies by removing the

126 1950-2017 mean for each calendar day, and then detrended prior to analyses. We also used the

127 winter monthly sea ice concentration (SIC) and sea surface temperature $(\mathrm{SST})$ data on a $1^{\circ} \times 1^{\circ}$

128 grid during 1950-2017 from the HadISST1 obtained from the Hadley Centre (Rayner et al. 
130 There are many ways to define the Interdecadal Pacific Oscillation (IPO) (Dai 2013; Dong 131 et al. 2018; Hua et al. 2018, 2019). As in van Oldenborgh et al. (2009), the winter IPO is 132 defined as the principal component (PC) of the first EOF of detrended, 4-year moving averaged 133 DJF-mean SST from HadISST1 over $50^{\circ} \mathrm{S}-50^{\circ} \mathrm{N}, 100^{\circ} \mathrm{E}-70^{\circ} \mathrm{W}$. Here, we used the winter IPO 134 index obtained from the Koninklijk Nederlands Meteorologisch Instituut (KNMI) Climate 135 Explorer. Following Trenberth and Shea (2006), we used the DJF-mean SST anomalies from 136 HadISST1 averaged over $0^{\circ}-60^{\circ} \mathrm{N}, 0^{\circ}-80^{\circ} \mathrm{W}$ minus the DJF-mean SST anomalies averaged over 137 the global oceans from $60^{\circ} \mathrm{S}-60^{\circ} \mathrm{N}$ as the Atlantic Multidecadal Oscillation (AMO) index, 138 which was also obtained from the KNMI Climate Explorer. Results are similar if the AMO 139 index from Kaplan et al. (1998) is used. Below, we will use the 9-year smoothed IPO and AMO 140 indices to examine the modulation of the IPO and AMO on UB and associated sub-seasonal 141 ECA to explain the change of the winter ECA from 1965-1976 to 2002-2013.

147 define the IPO/AMO combination. As in Huang et al. (2019), an IPO $^{-}$and $\mathrm{AMO}^{-}$(or $\left.\mathrm{IPO}^{-} / \mathrm{AMO}^{-}\right)$combination winter is defined if their normalized indices are negative below 0 STD, whereas an $\mathrm{IPO}^{-}$and $\mathrm{AMO}^{+}\left(\right.$or $\mathrm{IPO}^{-} / \mathrm{AMO}^{+}$) combination winter is defined if the 9-year 

combination winters are similarly defined. The results based on the 0.5 STD definition are 152 similar and given in the supplementary file.

153 To identify UB events in the Ural Mountains region around $60^{\circ} \mathrm{E}$, the one-dimensional (1D) blocking index of Tibaldi and Molteni (1990, TM hereafter) is used to calculate UB events over 155 the region $40^{\circ}-80^{\circ} \mathrm{E}$. The TM index is based on the reversal of the meridional gradient of Z500: $\mathrm{GHGN}=\frac{\mathrm{Z500}\left(\phi_{N}\right)-Z 500\left(\phi_{o}\right)}{\phi_{N}-\phi_{o}}$ and $\mathrm{GHGS}=\frac{\mathrm{Z500}\left(\phi_{o}\right)-Z 500\left(\phi_{S}\right)}{\phi_{o}-\phi_{S}}$ at three given latitudes $\phi_{N}=80^{\circ} N+\Delta, \phi_{o}=60^{\circ} N+\Delta, \phi_{S}=40^{\circ} N+\Delta$ and $\Delta=-5^{\circ}, 0^{\circ}, 5^{\circ}$. A blocking event is 158 defined to have taken place in a given region if both GHGS $>0$ and GHGN $<-10$ gpm (deg 159 lat $)^{-1}$ persist at least three consecutive days and are satisfied for at least one choice of $\Delta$. At the 160 same time, the duration of the UB is estimated as the consecutive days with the daily Z500 161 anomaly averaged over the blocking latitude band $\left(50^{\circ}-70^{\circ} \mathrm{N}\right)$ exceeding a threshold of 80 gpm, 162 and used to represent the local persistence time of the UB in the Ural region as in Luo et al. 163 (2018a). The change speed of the daily zonal location of the maximum anticyclonic anomaly averaged over $50^{\circ}-70^{\circ} \mathrm{N}$ is defined as the daily phase speed of $\mathrm{UB}$, whereas its time-mean value averaged over the blocking duration confined in the Ural region is defined as the mean movement speed of the UB. In our composite of UB events, the peak day of the GHGS is 167 defined as lag 0 day of the UB (B. Luo et al. 2017b).

Diao et al. (2006) evaluated the different blocking indices in identifying the blocking action

169 in the $\mathrm{NH}$ and demonstrated that the 1D TM index is an appropriate metric for identifying 170 blocking events over the Ural region. We compared different blocking indices (e.g., the 1D TM 
171 index and the PV- $\theta$ index of Masato et al. 2013a-b and Woollings et al. 2008), and found that

172 the UB events and their durations are not very sensitive to the choice of the blocking index

173 (Luo et al. 2018a, Tyrlis et al. 2020, 2021). Thus, in this paper we use only the 1D TM index to 174 identify UB events.

175 Our daily NAO index was taken from the NOAA /Climate Prediction Center. We also 176 define a $\mathrm{NAO}^{+}\left(\mathrm{NAO}^{-}\right)$event to have taken place if the daily NAO index is equal to or above 1770.5 (below -0.5) STDs and persists for at least three consecutive days. Other daily events are 178 defined as neutral $\mathrm{NAO}\left(\mathrm{NAO}^{\circ}\right)$ events if it is neither an individual $\mathrm{NAO}^{+}$nor $\mathrm{NAO}^{-}$event. The $179 \mathrm{UB}$ event can be defined as being related to the $\mathrm{NAO}^{+}\left(\mathrm{NAO}^{-}\right)$event and referred to as the $180 \mathrm{UB}^{-N A O}{ }^{+}\left(\mathrm{UB}_{-} \mathrm{NAO}^{-}\right)$event if the peak of the GHGS associated with the UB occurs within the 181 life cycle of the $\mathrm{NAO}^{+}\left(\mathrm{NAO}^{-}\right)$event (e.g., B. Luo et al. 2017). The $\mathrm{UB}^{-}$event with $\mathrm{NAO}^{\circ}$ is 182 referred to as the $\mathrm{UB}^{-\mathrm{NAO}^{\circ}}$ event.

183 We used the two-sided Student t-test for determining the statistical significance of the 184 anomaly field at each grid or the difference between two types of anomaly fields, but the Monte

185 Carlo test (using 5000 simulations generated by repeated random sampling) for the statistical 186 significance of the difference between two time series or between two duration lengths. Both tests are conducted at the $p<0.05$ level. These methods are described in Wilks (2011).

As demonstrated theoretically by Luo et al. (2019b) and Zhang and Luo (2020), the magnitude of the meridional potential vorticity $(\mathrm{PV})$ gradient $\left(\mathrm{PV}_{\mathrm{y}}\right)$ is a key factor influencing 190 the behavior (duration, movement and evolution) of atmospheric blocking. The

191 non-dimensional $\mathrm{PV}_{\mathrm{y}}$ at $500 \mathrm{hPa}$ is defined as $\mathrm{PV}_{y}=\beta-\frac{\partial \mathrm{U} 500}{\partial y}+F \mathrm{U} 500 \quad(F \approx 1$ for a 
192 barotropic atmosphere and $\beta$ is the non-dimensional meridional gradient of the Coriolis

193 parameter $f$ ), and $\mathrm{U} 500$ is the basic zonal wind at $500 \mathrm{hPa}$, which can be directly calculated

194 using non-dimensional DJF-mean 500-hPa zonal wind fields for blocking events excluded.

195 When $\mathrm{PV}_{\mathrm{y}}$ is small in the blocking region, atmospheric blocking has weak energy dispersion

196 and strong nonlinearity such that it can have a long lifetime (Luo et al. 2019b). The strength of

197 the upstream westerly wind or $\mathrm{PV}_{\mathrm{y}}$ is important for whether the blocking shows different

198 evolution (growth and decay) (Zhang and Luo 2020) and movement (Yao et al. 2017). When

199 the upstream westerly wind or $\mathrm{PV}_{\mathrm{y}}$ is weak, the atmospheric blocking exhibits rapid growth

200 and slow decay. The reverse is seen for a strong upstream westerly wind or a large upstream

201 PV $_{\mathrm{y}}$ (Zhang and Luo 2020). Below, we will use these insights to explain why the IPO or AMO

202 can influence the persistence, movement and evolution of the UB and their different impacts on

203 Eurasian temperatures by examining the changes in DJF-mean westerly wind and PV $_{\mathrm{y}}$ related

204 to the phase of IPO or AMO.

205 3. Decadal Eurasian cold anomalies and their linkage to UB events

206 a. Role of UB in the decadal Eurasian cold anomalies

207 Dai et al. (2015) and Deser et al. (2017) have noted that the recent global warming hiatus

208 was related to the decadal winter cold anomalies over Eurasia located mainly south of $60^{\circ} \mathrm{N}$.

209 Thus, it is useful to examine the physical cause of the decadal variability of the Eurasian cold

210 anomaly south of $60^{\circ} \mathrm{N}$. Figure 1a shows the time series of DJF-mean SAT anomalies averaged

211 over central Eurasia $\left(40^{\circ}-60^{\circ} \mathrm{N}, 60^{\circ}-120^{\circ} \mathrm{E}\right)$ from December 1950 to February 2018, with the

212 DJF-mean SLP and SAT anomaly patterns during 1965-1976 and 2002-2013 shown in Figs. 
213 1b-d. It is clear that winter cold anomalies occurred mainly during 1965-1976 (Fig. 1b) and

214 2002-2013 (Fig.1c), but the cold anomaly is stronger and extends more to west and south of

215 central Eurasia during 1965-1976 than during 2002-2013. This can be clearly seen from their

216 difference field (Fig.1d) with the SAT difference in the upstream region $\left(30^{\circ}-70^{\circ} \mathrm{E}\right)$ of Siberia

217 being statistically significant $(\mathrm{p}<0.05)$. The cause of such an interdecadal change has not been

218 examined in previous studies. However, when the UB events (i.e., the blocking days from lag

$219-10$ to 10 days with lag 0 denoting the peak day of the UB) and associated sub-seasonal ECAs

220 are removed from the DJF-mean SLP or Z500 and SAT fields, the winter ECAs become much

221 weaker in the south of $60^{\circ} \mathrm{N}$ for both 1965-1976 (Fig. 1e) and 2002-2013 (Fig. 1f) than those

222 with UB events (Figs. 1b-c). For this case, the significant cold anomaly is mainly located in the

223 north of $60^{\circ} \mathrm{N}$ (Figs. 1e-f). The difference of the DJF-mean SLP and SAT anomalies between

224 Figs. $1 \mathrm{~b}$ and 1e shows that the presence of the UB is crucial for the 1965-1976 winter ECA (Fig.

225 1g). But the difference between Figs. 1c and 1f indicates that the UB is also important for the

226 2002-2013 winter ECA (not shown). Thus, the above results suggest that the UB plays an

227 important role in causing the winter ECA over central Eurasia and its decadal change from

$228 \quad 1965-1976$ to 2002-2013 through the generation of sub-seasonal ECAs.

229 It should be noted that the warm anomaly over central Eurasia during 1980-2000 is related

230 to more $\mathrm{NAO}^{+}$events without UB (2.54 events per winter), compared to the lower frequencies

231 during 1965-1976 (1.25 events per winter) and 2002-2013 (1.83 events per winter). Because

232 the $\mathrm{NAO}^{+}$and $\mathrm{NAO}^{-}$events without UB cannot directly produce cold anomalies over central

233 Eurasia (Fig. S1 in the supplementary file), below we don't discuss the roles of $\mathrm{NAO}^{+}$and 
$234 \mathrm{NAO}^{-}$events without UB, but instead we examine the role of the UB in the sub-seasonal ECA.

235

236

237

238

239

240

241

242

243

244

245

246

247

248

249

250

251

252

253

254

Figs. 2a-d show the time series of the number of UB events in winter and the time-mean composite daily SLP and SAT anomalies averaged during the UB events from lag -10 to 10 days in three decadal epochs: 1965-1976, 1980-2000 and 2002-2013. Correspondingly, the time-longitude evolutions of composite daily Z500 anomalies averaged over $50^{\circ}-70^{\circ} \mathrm{N}$ during the UB life cycle are shown in Figs. 2e-g for 1965-1976, 1980-2000 and 2002-2013. It is found from Fig. 2a that there are 29, 30 and $21 \mathrm{UB}$ events (or 2.42, 1.43, and $1.75 \mathrm{UB}$ events per winter) during 1965-1976, 1980-2000, and 2002-2013, respectively. An increased trend of the UB events is seen during 2000-2013, which also corresponds to an increased trend of the UB duration (Luo et al. 2018, their Fig. 2). This is consistent with the result of Tyrlis et al. (2020, their Fig. 2) using the PV- $\theta$ index, who found that during 1990-2014 the trend in the warm Arctic-cold Siberia (WACS) pattern is related to the increasing winter UB frequency (the event frequency times duration). Because the difference of the UB event frequency between 1965-1976 and 2002-2013 is not statistically significant (at the $90 \%$ confidence level based on a Monte-Carlo test), the change of the winter UB event frequency cannot explain the Eurasian SAT change from 1965-1976 to 2002-2013.

To understand the mechanisms behind this change, Figs. 2b-d suggest that while the strong Eurasian cold anomalies mainly over central Eurasia during both 1965-1976 and 2002-2013 (Figs. 2b, d) are associated with long-lived UB events (Figs. 2e, g), the sub-seasonal ECA extends more southwest and covers a wider region in 1965-1976 (Fig. 2b) than in 2002-2013 (Fig. 2d) because UB is located in the upstream side of the Ural region during 1965-1976 
255 (Fig.2b). Such a sub-seasonal ECA difference is related to the difference of the UB in 256 longitudinal position, movement and evolution between 1965-1976 and 2002-2013. The UB 257 moves westward especially during the decaying phase and grows rapidly but decays slowly 258 during 1965-1976 (Fig. 2e), whereas it moves eastward and grows slowly but decays rapidly 259 during 2002-2013 (Fig. 2g). Thus, it is inferred that the sub-seasonal ECA with an enhanced 260 upstream (downstream) cold anomaly during 1965-1976 (2002-2013) is likely related to the 261 westward movement, rapid growth and slow decay (eastward movement, slow growth and 262 rapid decay) of long-lived UBs (Figs. 2e, g). As the UB is displaced westward during 263 1965-1976, the cold Arctic air can reach farther west and south of central Eurasia through the 264 cold temperature advection associated with low-level winds (Fig. S2a) (Yao et al. 2017) and 265 induce a strong upstream cold anomaly (Figs. 2b, e). In contrast, strong cold anomalies are 266 easily seen over central and eastern Asia during 2002-2013 (Fig. 2d) because of the eastward 267 shift of the cold temperature advection (Fig. S2c) related to the eastward movement of UB 268 (Figs. 2g). Moreover, because the UBs have a shorter duration and move rapidly westward 269 during 1980-2000 (Fig. 2f), the Eurasian warm anomaly during 1980-2000 is also related to 270 short-lived and rapidly retrograde UB events during this period.

271 We note here that we do not investigate the changes of Eurasian air temperatures from 272 1965-1976 to $1980-2000$ or from $1980-2000$ to $2002-2013$, as our emphasis is on the 273 exploration of the physical cause of the interdecadal change of the winter ECA from 1965-1976 274 to 2002-2013. The calculation shows that the UB has a longer duration of about 9 days (11 days) 275 over $40^{\circ}-80^{\circ} \mathrm{E}$ with a movement speed of $-1.4 \mathrm{~m} / \mathrm{s}(1.6 \mathrm{~m} / \mathrm{s})$ during $1965-1976(2002-2013)$ 
276 (Figs. 2e, g) than that of about 7 days with a large retrogression speed of $-2.2 \mathrm{~m} / \mathrm{s}$ during 277 1980-2000 (Fig. 2f). While the UB's duration difference between 1965-1976 and 2002-2013 is 278 not statistically significant for a Monte-Carlo test, the UB shows opposite movement and 279 evolution (growth and decay) between the two periods. Thus, the difference of the winter ECA 280 spatial patterns between 1965-1976 (Fig. 1b) and 2002-2013 (Fig. 1c) is mainly related to the 281 different longitudinal position, movement and evolution of long-lived UBs in the two periods 282 (Figs. 2e, g). These results are not noted in previous studies (Luo et al. 2017b and B. Luo et al. 283 2019). 1965-1976 to 2002-2013 is similar to the 1965-1976 minus 2002-2013 winter ECA difference (Fig. 1d) and whether such a change is mainly related to the interdecadal variation of the $\mathrm{UB}^{-N A O}{ }^{+}$events because most of the UB events are related to $\mathrm{NAO}^{+}$(Luo et al. 2016b). Our calculation reveals that there are 67 UB-NAO ${ }^{+}(53 \%)$ events out of the $126 \mathrm{UB}$ events, but 30 UB-NAO $^{-}(24 \%)$ events and 29 UB-NAO $^{\circ}$ (23\%) events during 1950-2017. On average, $\mathrm{UB}^{-N A O}{ }^{+}$events (1.17 and 1.08 cases per winter) during 1965-1976 and 2002-2013 are more frequent than $\mathrm{UB}^{-\mathrm{NAO}^{-}}$events $\left(0.67\right.$ and 0.42 cases per winter) and $\mathrm{UB}^{-\mathrm{NAO}^{\circ}}$ events $(0.58$ and 0.22 cases per winter). Figs. 3a-d show the horizontal fields of time-mean composite daily Z500 and SAT anomalies averaged from lag-10 to 10 days of UB and UB-NAO ${ }^{+}$events during 1950-2017 and their differences between 1965-1976 and 2002-2013. It is found that the spatial pattern of the UB-induced cold anomaly for UB-NAO ${ }^{+}$events (Fig. 3b) is similar to that for all UB events (Fig.3a), although UB-NAO ${ }^{-}$and $\mathrm{UB}^{-N_{A} O^{\circ}}$ events influence the cold anomalies 
over central Eurasia during 1965-1976 and 2002-2013 (not shown). The difference of the

298 UB-induced sub-seasonal cold anomaly between 1965-1976 and 2002-2013 (Fig.3c) also

299 resembles the DJF-mean SAT difference between the two periods (Fig. 1d), which is mainly

300 related to the change of $\mathrm{UB}^{-N_{A O}}{ }^{+}$events from 1965-1976 to 2002-2013 (Fig. 3d) because the

$301 \mathrm{UB}$ with $\mathrm{NAO}^{+}$(Figs. 3e, f) shows similar behaviors in persistence, movement and evolution to

302 those of all UB events (Figs. 2e, g). Thus, we do not classify UB events in terms of the phase of

303 NAO in our following discussions. Instead, we examine the effects of background conditions

304 associated with AMO and IPO on the UB and associated cold anomaly as well as their changes

305 from 1965-1976 to 2002-2013 in the next sections.

306

307

308

309

310

311

312

313

314

315

316

317

\section{Interdecadal variations of UB events and associated sub-seasonal cold anomalies and}

\section{their linkage to IPO and AMO}

\section{a. Interdecadal SST modes and their linkages to IPO and AMO}

Figures $4 \mathrm{a}-\mathrm{b}$ show the time series of normalized DJF-mean IPO and AMO indices during 1950-2017. In addition, we show the DJF-mean SST anomalies averaged over 1965-1976 and 2002-2013 in Figs. 4c-d, whereas the regressed DJF-mean SST anomalies onto the 9-year smoothed IPO and AMO indices are shown in Figs. 4e-f. It is shown that the winter IPO experienced a positive phase (IPO ${ }^{+}$) during 1960-1968, 1979-1998 and 2015-2017; but a negative phase (IPO-) during 1950-1959, 1960-1978 and 2000-2014 (Fig. 4a). The winter AMO had a positive phase $\left(\mathrm{AMO}^{+}\right)$during 1950-1960 and 1996-2017; but a negative phase (AMO') during 1960-1995 (Fig. 4b). Our calculation also revealed that there are $16 \mathrm{IPO}^{-}$and $19 \mathrm{IPO}^{+}$as well as $22 \mathrm{AMO}^{-}$and $18 \mathrm{AMO}^{+}$winters based on the $0.5 \mathrm{STD}$ definition of the 9-year 
smoothed IPO and AMO indices during 1950-2017.

Clearly, the SST anomaly patterns resemble those for IPO- and AMO- during 1965-1976 (Fig. 4c), but for $\mathrm{IPO}^{-}$and $\mathrm{AMO}^{+}$during 2002-2013 (Fig. 4d). The regressed SST anomalies show that while the $\mathrm{IPO}^{-}$mode corresponds to a weak $\mathrm{AMO}^{+} \mathrm{SST}$ anomaly over North Atlantic (Fig. 4e), the $\mathrm{AMO}^{+}$mode can correspond to an IPO- SST anomaly over the Pacific (Fig. 4f), although weaker than that of the IPO- mode (Fig. 4e). Because the relationship between IPO and AMO has been discussed in detail in other studies (e.g., Zhang and Delworth 2007; Meehl et al. 2021), examining their mutual relationship is beyond the scope of our present study. A comparison between Figs. 4e-f and Figs. 4c-d leads us to infer that the 1965-1976 ECA is likely related to the $\mathrm{IPO}^{-}$and $\mathrm{AMO}^{-}$modes or their combination, whereas the 2002-2013 ECA is related to the $\mathrm{IPO}^{-}$and $\mathrm{AMO}^{+}$modes or their combination.

\section{b. Modulation of IPO and AMO on the UB and sub-seasonal cold anomalies}

In this subsection, a composite of DJF-mean Z500 and SAT anomalies with and without UB events in $\mathrm{IPO}^{-}, \mathrm{AMO}^{-}$and $\mathrm{AMO}^{+}$winters is first shown in Fig. 5 to help us consider whether IPO and AMO without UB contribute to the winter ECAs. Figure 5a shows that the $\mathrm{IPO}^{-}$with UB corresponds to a strong winter cold anomaly over central Eurasia. But when UB events are excluded from the $\mathrm{IPO}^{-}$winters, no strong cold anomaly appears over central Eurasia, but mainly north of $60^{\circ} \mathrm{N}$ for IPO- (Fig. 5b). For $\mathrm{AMO}^{+}$there is no strong ECA for both cases with and without UB (Figs. 5c-d). For $\mathrm{AMO}^{-}$a relatively strong cold anomaly appears in the upstream and south sides of central Eurasia (Fig. 5e), but almost disappears when the UB events are excluded (Fig. 5f). Thus, AMO $^{-}$without UB cannot produce interdecadal cold 
339 anomalies in the south of $60^{\circ} \mathrm{N}$ over Eurasia, but can correspond to strong high latitude cold

340 anomalies over Eurasia (north of $60^{\circ} \mathrm{N}$ ). Similar results are found using the zero (instead of

$341 \pm 0.5)$ threshold for defining the IPO and AMO phases (Fig. S3). Thus, although $\mathrm{AMO}^{+}$or

$342 \mathrm{AMO}^{-}$cannot produce strong cold anomaly over central Eurasia south of $60^{\circ} \mathrm{N}$ as seen in

343 observations (Fig. 1b-c) if the UB is absent, $\mathrm{IPO}^{-}$without $\mathrm{UB}$ cannot contribute to the

344 interdecadal cold anomalies over central Eurasia (Fig.5b). These results suggest that UB events

345 modulated by $\mathrm{IPO}^{-}, \mathrm{AMO}^{-}$and $\mathrm{AMO}^{+}$play an important role in the winter cold anomaly over

346 central Eurasia. By comparison, the interdecadal cold anomaly during IPO- without UB in the

347 winter ECA is weak only with a small area of cold anomaly in the downstream side of $120^{\circ} \mathrm{E}$.

348 Figure 6 shows the time series of winter UB events for IPO-, IPO ${ }^{+}, \mathrm{AMO}^{-}$and $\mathrm{AMO}^{+}$.

349 There are $36(34)$ total events or 2.25 (1.79) UB events per winter during IPO- $\left(\right.$ IPO $\left.^{+}\right)\left(\right.$Figs. $^{2}$

350 6a-b), but 43 (33) total events or 1.95 (1.83) UB events per winter during ' $\mathrm{AMO}^{-}\left(\mathrm{AMO}^{+}\right)$(Figs.

$3516 \mathrm{c}-\mathrm{d})$. Thus, the UB event number does not vary greatly among the $\mathrm{IPO}^{-}, \mathrm{IPO}^{+}, \mathrm{AMO}^{-}$and

$352 \mathrm{AMO}^{+}$phases. This is expected because the UB (mostly UB-NAO ${ }^{+}$) events are mainly excited

353 by the decay of the $\mathrm{NAO}^{+}$through energy dispersion or wave train propagation (Luo et al.

$3542016 b, 2018 b$ ), which does not strongly depend on the phase of IPO or AMO. However, the

355 IPO or AMO can modulate the decadal background condition and significantly affect the

356 longitudinal position, duration, movement and evolution of the UB events.

357 To understand how the phase of IPO or AMO influences the behaviors of UB and 358 associated sub-seasonal ECA, we show the time-mean composites of daily Z500 and SAT 359 anomalies averaged from lag -10 to 10 days of the UB events and time-longitude evolutions of 
360 the composite daily Z500 anomalies averaged over $50^{\circ}-70^{\circ} \mathrm{N}$ in Figs. 7-8 for the two phases of

361 IPO and AMO, respectively. It is seen that a strong sub-seasonal ECA appears over central

362 Eurasia and its upstream side during the UB events for IPO- (Fig. 6a) as the UB has a strong 363 negative height anomaly at $60^{\circ} \mathrm{E}$ and its east side, a long duration of about 9.5 days with rapid

364 growth and persistent slow decay, and a small westward speed of about $-0.2 \mathrm{~m} / \mathrm{s}$ in the Ural 365 region mainly occurring after lag 3 (Fig. 7d). The UB is mainly located in the upstream side of 366 Ural region. In contrast, a weak ECA is seen for $\mathrm{IPO}^{+}$(Fig. 7b) as the UB has a very weak 367 negative Z500 anomaly, a short lifespan ( $\sim 7$ days), and a large retrogression speed of about -2.0 $\mathrm{m} / \mathrm{s}$ but without rapid growth and persistent slow decay (Fig. 7e). Thus, the UB has a larger contribution to the cold anomaly upstream of central Eurasia during $\mathrm{IPO}^{-}$than during $\mathrm{IPO}^{+}$ because of the westward displacement and long lifetime of UB and its rapid growth and slow 371 decay during IPO-

A relatively strong cold anomaly is seen over central Eurasia and its upstream side during the UB events for $\mathrm{AMO}^{-}$(Fig. 8a) as the UB has a negative height anomaly around $40^{\circ}-120^{\circ} \mathrm{E}$, a relatively short duration ( $\sim 7$ days), a westward movement of about $-1.0 \mathrm{~m} / \mathrm{s}$ (Fig. $8 \mathrm{~d}$ ) and a 375 distinct slow decay but weaker than that during IPO- (Fig.7d). But the UB corresponds to a 376 strong cold anomaly over central Eurasia and its downstream side for $\mathrm{AMO}^{+}$(Fig. $8 \mathrm{~b}$ ) because 377 it shows slow growth and rapid decay with a duration of $\sim 9$ days and a large eastward speed of 378 about $1.5 \mathrm{~m} / \mathrm{s}$ (Fig. 8e). The UB duration difference of $\sim 2$ (3) days is significant at the $90 \%$ 379 (95\%) confidence level based on a Monte-Carlo test with 5000 simulations. These UB 380 differences in longitudinal position, movement and duration lead to a large difference in the 
381 cold anomaly in the upstream and downstream sides of central Eurasia between $\mathrm{AMO}^{+}$and $382 \mathrm{AMO}^{-}$(Fig. 8c). Thus, a comparison of Fig. 7 with Fig. 8 reveals that although $\mathrm{AMO}^{+}$plays an 383 important role in the downstream cold anomaly associated with the UBs (Fig. 8b) because of 384 the long lifetime, eastward movement, slow growth and rapid decay of the composite UB, the 385 UB-induced sub-seasonal ECA is located more west- and south-ward during IPO- than during $386 \mathrm{AMO}^{+}$, whereas $\mathrm{AMO}^{-}$contributes to the upstream cold anomaly through retrograde UBs with 387 a slow decay. of UB-induced sub-seasonal ECAs modulated by IPO and AMO?

Because 1965-1976 includes both $\mathrm{IPO}^{-}$and $\mathrm{AMO}^{-}$winters and 2002-2013 corresponds to both $\mathrm{IPO}^{-}$and $\mathrm{AMO}^{+}$winters, it is instructive to examine the change of the UB-induced sub-seasonal ECA from $\mathrm{IPO}^{-}$to $\mathrm{AMO}^{+}$or from $\mathrm{IPO}^{-}$to $\mathrm{AMO}^{-}$to understand whether the change of the winter ECA from 1965-1976 to 2002-2013 is mainly related to the interdecadal changes of UB-induced sub-seasonal ECAs modulated by $\mathrm{IPO}^{-}, \mathrm{AMO}^{-}$and $\mathrm{AMO}^{+}$. We show time-mean composites of the daily Z500 and SAT anomalies averaged from lag -10 to 10 days of UB events for $\mathrm{IPO}^{-}$during 1965-1976 and $\mathrm{AMO}^{+}$during 2002-2013 in Figs. 9a-b. Their difference fields between 1950-2017 and 1965-1976 for IPO-, between 1950-2017 and 2002-2013 for $\mathrm{AMO}^{+}$, between $\mathrm{IPO}^{-}$and $\mathrm{AMO}^{+}$during 1950-2017, and between $\mathrm{IPO}^{-}$during 1965-1976 and $\mathrm{AMO}^{+}$during 2002-2013 are shown in Figs. 9c-f. It is found that the UB-induced cold anomaly mainly occurs over central Eurasia and its upstream side for IPO- during 1965-1976 (Fig. 9a), but over central Eurasia and its downstream side for $\mathrm{AMO}^{+}$during 2002-2013 (Fig.9b). 
402 Although Fig. 9c shows that for IPO- the strength of the UB-induced cold anomaly is slightly 403 stronger during 1965-1976 than during 1950-2017, the spatial structure of the cold anomaly 404 during 1965-1976 is consistent with that during 1950-2017. A similar feature is found for $405 \mathrm{AMO}^{+}$(Fig. 9d). This result leads us to infer that the spatial structure of the UB-induced cold 406 anomaly over Eurasia does not strongly depend on the sample size of the UB events, but is 407 significantly influenced by the phase of IPO or AMO. We also found that the IPO- minus $^{-}$ $408 \mathrm{AMO}^{+}$difference during 1950-2017 (Fig.9e) resembles the difference between IPO- during 409 1965-1976 and $\mathrm{AMO}^{+}$during 2002-2013 (Fig. 9f). Thus, the decadal variation of UB-induced 410 cold anomaly from $1965-1976$ to $2002-2013$ can be, to a large extent, explained by the change 411 of the UB events associated with the transition from IPO- ${ }^{-}$to $\mathrm{AMO}^{+}$during $1950-2017$.

412 We show the time series of domain-averaged composite daily SAT anomalies over the 413 upstream $\left(30^{\circ}-70^{\circ} \mathrm{E}, 30^{\circ}-50^{\circ} \mathrm{N}\right)$ and downstream $\left(90^{\circ}-130^{\circ} \mathrm{E}, 30^{\circ}-50^{\circ} \mathrm{N}\right)$ regions of the UB 414 events during the blocking life cycle (from lag -20 to 20 days) for $\mathrm{IPO}^{-}, \mathrm{AMO}^{-}$and $\mathrm{AMO}^{+}$in 415 Figs. 10a-f during 1950-2018, 1965-1976 and 2002-2013. It is found that UBs during AMO $^{-}$ 416 and $\mathrm{IPO}^{-}$contribute to strong cold anomalies in the upstream region of central Eurasia (Figs. 417 10a, c). IPO- (Fig. 10a) plays a more important role in the UB-induced cold anomaly in the 418 upstream side of Eurasia than $\mathrm{AMO}^{-}$or $\mathrm{AMO}^{+}$(Fig. 10c), even though the upstream cold 419 anomaly is stronger during 1965-1976 (blue line in Fig.10e) than during 1950-2017 (blue line 420 in Fig.10a). During 1965-1976, the UB-induced cold anomaly also extends more to the west 421 and south of Eurasia for $\mathrm{IPO}^{-}$than $\mathrm{AMO}^{-}$as seen from the $\mathrm{IPO}^{-}$minus $\mathrm{AMO}^{-}$difference (Fig.

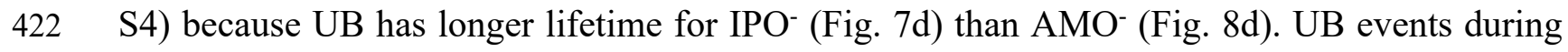


$423 \mathrm{AMO}^{+}$contribute slightly more to the cold anomaly downstream of Eurasia than during $\mathrm{IPO}^{-}$

424 and $\mathrm{AMO}^{-}$(Figs. 10b, d, f). These results suggest that the decadal change of the winter ECA

425 from 1965-1976 to 2002-2013 (Fig.1d) is not only related to the interdecadal variations of the

426 UB-induced sub-seasonal ECAs modulated by $\mathrm{IPO}^{-}$and $\mathrm{AMO}^{+}$, but also related to retrograde

427 UBs during $\mathrm{AMO}^{-}$winters.

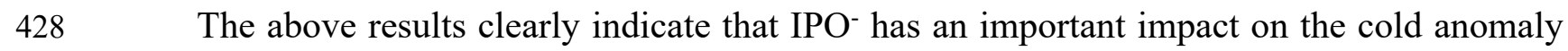

429 over the upstream region and southwestern Eurasia through the rapid growth and slow decay of

430 westward-displaced $\mathrm{UB}$, whereas $\mathrm{AMO}^{+}$exerts a large effect on the cold anomaly over the

431 downstream region through the eastward movement, slow growth and rapid decay of the UBs.

432 As noted below, the IPO and AMO can influence the UB through different background

433 conditions. Thus, these different effects of $\mathrm{IPO}^{-}$or $\mathrm{AMO}^{-}$and $\mathrm{AMO}^{+}$, combined with the

434 interdecadal variations in the UB events, can lead to interdecadal changes in the spatial patterns 435 of the winter ECA.

436 Because the $\mathrm{IPO}^{-}$winters includes $\mathrm{AMO}^{-}$and $\mathrm{AMO}^{+}$as well as the $\mathrm{AMO}^{+}$winters includes

$437 \mathrm{IPO}^{-}$and $\mathrm{IPO}^{+}$, it is also useful to examine how the different IPO/AMO combinations modulate

438 the UB and UB-induced sub-seasonal ECA. Following the above definition of the IPO and

439 AMO phase combination we show winter UB events during $\mathrm{IPO}^{-} / \mathrm{AMO}^{-}, \mathrm{IPO}^{-} / \mathrm{AMO}^{+}$,

$440 \mathrm{IPO}^{+} / \mathrm{AMO}^{-}$and $\mathrm{IPO}^{+} / \mathrm{AMO}^{+}$winters in Fig.11a. It is found that there are $10 \mathrm{IPO}^{-} / \mathrm{AMO}^{-}, 24$

$441 \mathrm{IPO} / \mathrm{AMO}^{+}, 22 \mathrm{IPO}^{+} / \mathrm{AMO}^{-}$and $8 \mathrm{IPO}^{+} / \mathrm{AMO}^{+}$combination winters during 1950-2017, which

442 correspond in turn to $25,43,42$ and $16 \mathrm{UB}$ events or $2.5,1.79,1.91$ and $2 \mathrm{UB}$ events per winter

443 (Fig.11a). We show time-mean composite daily Z500 and SAT anomalies averaged from lag -10 
444 to 10 days of UB events in Figs. $11 \mathrm{~b}-\mathrm{g}$ for these combinations. We can see that UB events are 445 most frequent in the IPO-/AMO- winters and occurred during 1969-1978. In the $\mathrm{IPO}^{-} / \mathrm{AMO}^{+}$ 446 winters UB events occurred during 1950-1959 and 2000-2014 (Fig. 11a). The UB corresponds 447 to strong sub-seasonal cold anomalies over central Eurasia for the $\mathrm{IPO}^{-} / \mathrm{AMO}^{-}$and $\mathrm{IPO}^{-} / \mathrm{AMO}^{+}$ 448 combinations (Figs.11b-c), although this cold anomaly is stronger and located more southwest 449 in the $\mathrm{IPO}^{-} / \mathrm{AMO}^{-}$winter (Fig. 11b) than in the $\mathrm{IPO}^{-} / \mathrm{AMO}^{+}$winter (Fig. 11c). In contrast, the 450 UB-induced cold anomalies are weak over central Eurasia in the $\mathrm{IPO}^{+} / \mathrm{AMO}^{-}$and $\mathrm{IPO}^{+} / \mathrm{AMO}^{+}$ 451 combination winters (Figs. 11e-f). The UB-induced cold anomaly for the $\mathrm{IPO}^{-} / \mathrm{AMO}^{-}$ 452 combination has a spatial pattern similar to that for IPO- $^{-}$or AMO- $^{-}$in 1965-1976 (Figs. 10a, d). 453 In the $\mathrm{IPO}^{-} / \mathrm{AMO}^{+}$combination winter, the UB-induced cold anomaly pattern (Fig. 11c) is 454 analogous to that for the $\mathrm{AMO}^{+}$(Fig. 8b). It is further found that the difference of the 455 UB-induced SAT anomaly field between the IPO-/AMO ${ }^{-}$and $\mathrm{IPO}^{-} / \mathrm{AMO}^{+}$combination winters 456 (Fig. 11d) has a large similarity with the $\mathrm{IPO}^{-}$minus $\mathrm{AMO}^{+}$difference (Fig. 9e) or the $\mathrm{AMO}^{-}$ 457 minus $\mathrm{AMO}^{+}$difference (Fig. 8c), even though the $\mathrm{AMO}^{-}$minus $\mathrm{AMO}^{+}$difference is relatively 458 weak. To some extent, the change of the UB-induced ECA from the $\mathrm{IPO}^{-} / \mathrm{AMO}^{-}$combinations 459 during $1965-1976$ to the $\mathrm{IPO}^{-} / \mathrm{AMO}^{+}$combinations during 2002-2013 is also similar to the 460 interdecadal change of UB-induced sub-seasonal ECA from $\mathrm{IPO}^{-}$to $\mathrm{AMO}^{+}$or from $\mathrm{AMO}^{-}$to $461 \mathrm{AMO}^{+}$. A similar result is found for the IPO/AMO combination based on the 0.5 STD 462 definition (Fig.S5).

\section{5. Atmospheric link between IPO/AMO and Ural blocking and ECA}

464 In this section, we reveal why the phase of IPO or AMO can modulate the UB and why a 
465 large SIC decline over BKS is unnecessary for the change of UB during IPO-, which occurred 466 during 1965-1976, but necessary for the UB change during $\mathrm{AMO}^{+}$, which occurred during $467 \quad 2002-2013$.

468 Figure 12 shows the regression patterns of DJF-mean U500, $\mathrm{PV}_{\mathrm{y}}$ at $500 \mathrm{hPa}$ and SIC 469 anomalies against the 9-year smoothed DJF-mean IPO and AMO indices shown in Figs. 4a-b.

470 It is seen that during IPO- there are negative U500 anomalies in the North Atlantic mid-high 471 latitudes $\left(42^{\circ}-60^{\circ} \mathrm{N}\right)$ with a center near $50^{\circ} \mathrm{N}$ to the north of the Gulf Stream Extension (GSE) 472 and over Eurasian high latitudes (north of $50^{\circ} \mathrm{N}$ ) (Fig.12a). But during $\mathrm{AMO}^{+}$there is a positive 473 U500 anomaly over the high latitudes $\left(50^{\circ}-65^{\circ} \mathrm{N}\right)$ centered near $60^{\circ} \mathrm{N}$ to the north of GSE and a 474 negative anomaly over the Ural Mountains and their east side (Fig. 12b). A reversed westerly 475 wind pattern is seen for $\mathrm{IPO}^{+}$or $\mathrm{AMO}^{-}$. The zonal wind patterns during $\mathrm{IPO}^{-}$are consistent with 476 the result of Dong and Dai (2015, their Fig.11). While $\mathrm{PV}_{\mathrm{y}}$ is weak (strong) in the North 477 Atlantic mid-high latitudes for IPO- $\left(\mathrm{AMO}^{+}\right)$, it is weak in Eurasian high latitudes near the Ural 478 region (Figs. 12c-d). Although the negative $\mathrm{U} 500$ or $\mathrm{PV}_{\mathrm{y}}$ anomaly is insignificant over the

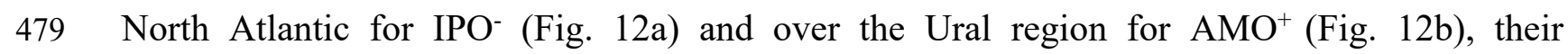
480 differences between $\mathrm{IPO}^{-}$and $\mathrm{AMO}^{+}$are statistically significant $(\mathrm{p}<0.05)$ based on a two-sided 481 Student t-test (not shown). Thus, the North Atlantic zonal wind and $\mathrm{PV}_{\mathrm{y}}$ patterns show opposite 482 changes between $\mathrm{IPO}^{-}$and $\mathrm{AMO}^{+}$, although they are weak in the Ural region. In summary, 483 weak zonal winds and small $\mathrm{PV}_{\mathrm{y}}$ are seen in the region from the south side of Greenland to the 484 Ural region and its east side for $\mathrm{IPO}^{-}$. But for $\mathrm{AMO}^{+}$zonal winds and $\mathrm{PV}_{\mathrm{y}}$ are strong in the 485 south side of Greenland and weak in the Ural region. 
According to the theoretical result of Zhang and Luo (2020), the UB shows rapid growth and slow decay when upstream background westerly winds and $\mathrm{PV}_{\mathrm{y}}$ are weak as seen during IPO- In contrast, the UB shows an enhanced eastward movement, slow growth and rapid decay when upstream background westerly winds and $\mathrm{PV}_{\mathrm{y}}$ are relatively strong as seen during $\mathrm{AMO}^{+}$. Thus, these results explain why the UB shows an opposite change in movement and evolution between $\mathrm{IPO}^{-}$and $\mathrm{AMO}^{+}$as seen in Figs. $7 \mathrm{~d}$ and 8e. We also see that weak high-latitude westerly winds and small $\mathrm{PV}_{\mathrm{y}}$ over Eurasia can occur without strong BKS warming or SIC decline for IPO- (Luo et al. 2019a) because IPO- corresponds to an interdecadal cold anomaly in Eurasian high latitudes (the north of $60^{\circ} \mathrm{N}$ ) (Figs. 5b) as seen during 1965-1976 (Fig.1e). Thus, the BKS SIC anomaly may be positive for IPO- $^{-}$(Fig. 12e), indicating that a low BKS SIC is not needed for the maintenance of $\mathrm{UB}$ for $\mathrm{IPO}^{-}$, whereas $\mathrm{AMO}^{-}$has a similar effect. But a large BKS sea-ice loss is needed for increased persistence of $\mathrm{UB}$ for $\mathrm{AMO}^{+}$(Fig. 12f) because the warm anomaly background is dominant over Eurasian mid-high latitudes for $\mathrm{AMO}^{+}$(Fig. 5d) as occurred during 2002-2013 (Fig. 1f).

The above results explain why a strong winter ECA can occur during 1965-1976 even when $\mathrm{IPO}^{-}$or $\mathrm{AMO}^{-}$dominates and a large BKS SIC decline is absent (Fig. 12e). In contrast, the BKS warming and thus SIC decline must be strong for $\mathrm{AMO}^{+}$so that the winter ECA can occur during 2002-2013. Our finding here does not contradict the results of Mori et al. (2014), who showed a robust Eurasian cooling in the ensemble-mean response to recent Arctic sea-ice loss (but not in individual realizations), because our result can not only explain why the BKS SIC decline must be strong for the ECA during 2002-2013, but also explain why the BKS SIC 
507

508

509

510

511

512

513

514

515

516

517

anomaly can be positive for the ECA during 1965-1976. Furthermore, greenhouse gas-induced warming and sea-ice loss are unlikely to cause cooling over Eurasia (Dai and Song 2020); thus, the ECA more likely results from internal decadal variations of UB associated with internal modes such as the IPO, AMO and Arctic decadal variations.

The above results reveal that $\mathrm{AMO}^{+}$favors eastward-moving, slowly growing and rapidly decaying UBs over Eurasia through the intensifying (weakening) of high-latitude westerly winds and $\mathrm{PV}_{\mathrm{y}}$ over the North Atlantic (Eurasia), whereas IPO- promotes the slow westwardmoving, rapidly growing and slowly decaying UBs through the weakening of high-latitude westerly winds and $\mathrm{PV}_{\mathrm{y}}$ from the North Atlantic to Eurasia. But UBs are relatively short-lived and retrograde during $\mathrm{AMO}^{-}$and $\mathrm{IPO}^{+}$because the zonal winds and $\mathrm{PV}_{\mathrm{y}}$ conditions are opposite to those during $\mathrm{AMO}^{+}$and $\mathrm{IPO}^{-}$.

\section{Summary and Conclusions}

In this paper, we first examined the dependence of winter Ural blocking (UB) and its impact on Eurasian surface air temperature (SAT) on the phase of IPO and AMO as defined by 9-year smoothed IPO and AMO indices, and then combined the recent IPO and AMO phases to physically explain the interdecadal difference in the winter Eurasian cold anomaly (ECA) between 1965-1976 and 2002-2013. A strong winter ECA is found to occur more in the upstream and southwestern side of central Eurasia during 1965-1976 than during 2002-2013. This interdecadal change is found to be mainly related to $\mathrm{IPO}^{-}$and $\mathrm{AMO}^{+}$through their modulation of the Ural blocking (UB) in its movement, persistence and evolution (rather than in its event numbers), whereas $\mathrm{AMO}^{-}$contributes to the 1965-1976 ECA through retrograde 
528 slowly decaying UBs. In contrast, without the UB the impact of $\mathrm{IPO}^{-}$and $\mathrm{AMO}^{-}$on the cold

529 SAT anomaly is mainly confined to the north of $60^{\circ} \mathrm{N}$ over Eurasia. We propose a new pathway

530 of the IPO/AMO-ECA connection, which works by means of the UB change due to the

531 changed background condition associated with the phase of the IPO or AMO: different

532 IPO/AMO phases lead to different background conditions in zonal winds and $\mathrm{PV}_{\mathrm{y}}$ over the

533 North Atlantic and Eurasia, which affect the characteristics of UB, which in turn affect SAT

534 over Eurasia through cold advection.

535 The 1965-1976 period was dominated by a negative phase IPO (IPO-) in combination with

536 a negative phase $\mathrm{AMO}\left(\mathrm{AMO}^{-}\right)$, while a positive phase $\mathrm{AMO}\left(\mathrm{AMO}^{+}\right)$in combination with

$537 \mathrm{IPO}^{-}$are frequent during 2002-2013. Although the event frequency of winter UB events does

538 not strongly depend on the phase of IPO or AMO during 1950-2017, we found that the UB is

539 long-lived and shows rapid growth, slow decay and retrogression during the decaying phase

540 (eastward movement, slow growth and rapid decay) during $\mathrm{IPO}^{-}\left(\mathrm{AMO}^{+}\right)$, but is relatively

541 short-lived and retrograde during both $\mathrm{IPO}^{+}$and $\mathrm{AMO}^{-}$. During $\mathrm{IPO}^{-}$the UB leads to a strong

542 cold anomaly with a southwestward extension of central Eurasia through advection of cold

543 Arctic air into these regions. During $\mathrm{AMO}^{+}$the UB induces strong cold anomalies over central

544 Eurasia and its downstream side through advection of cold Arctic air. It is found that the change

545 of the winter ECA from 1965-1976 to 2002-2013 is mainly related to the different influences of

546 the $\mathrm{IPO}^{-}, \mathrm{AMO}^{-}$and $\mathrm{AMO}^{+}$on the longitudinal position, persistence, movement and evolution

547 of UB. The difference of the UB-induced sub-seasonal cold anomaly between the IPO-/AMO-

548 and $\mathrm{IPO}^{-} / \mathrm{AMO}^{+}$combination winters more resembles the $\mathrm{IPO}^{-}$minus $\mathrm{AMO}^{+}$difference than 
the $\mathrm{AMO}^{-}$minus $\mathrm{AMO}^{+}$difference.

550 It is further revealed that during $\mathrm{IPO}^{-}$without $\mathrm{UB}$ the background zonal winds and 551 meridional $\mathrm{PV}$ gradient $\left(\mathrm{PV}_{\mathrm{y}}\right)$ over Eurasian high latitudes are weakened due to reduced 552 meridional temperature gradients and intensified PV anomalies related to strong background 553 cold anomaly in the high-latitude Eurasia (Fig. 5b) without strong warming or SIC decline over 554 Barents-Kara Seas (BKS). Such zonal wind and $\mathrm{PV}_{\mathrm{y}}$ changes over Eurasian high latitudes favor 555 long-lived UBs, which are also seen during $\mathrm{AMO}^{+}$and related to a strong warming or SIC 556 decline in BKS because the background warm anomaly prevails over Eurasian mid-high 557 latitudes. During $\mathrm{IPO}^{-}\left(\mathrm{AMO}^{+}\right)$weakened (intensified) westerly winds are also seen over the 558 North Atlantic high latitudes because of the presence of weak positive Z500 anomalies over the 559 North Atlantic north (south) of $60^{\circ} \mathrm{N}$ (Dong and Dai 2015), which lead to the rapid growth, 560 slow decay and retrogression of UB during its decaying phase (slow growth, rapid decay and 561 eastward movement of $\mathrm{UB})$ during $\mathrm{IPO}^{-}\left(\mathrm{AMO}^{+}\right)$. The reversed zonal wind patterns are seen for $562 \quad \mathrm{IPO}^{+}\left(\mathrm{AMO}^{-}\right)$

563 In summary, our main results are that the large difference in UB's position, movement and 564 evolution between IPO-, $\mathrm{AMO}^{-}$and $\mathrm{AMO}^{+}$is important for the interdecadal variation of the 565 winter ECA from 1965-1976 to 2002-2013. A large BKS warming (or SIC decline) is necessary 566 for the generation of the winter ECA for $\mathrm{AMO}^{+}$, but is not necessary for IPO-. Rudeva and 567 Simmonds (2021) have also pointed to the role of the high-latitude background wind field in 568 permitting or denying the establishment of quasi-stationary teleconnection patterns. 569 Specifically, IPO- influences the ECA via the following pathway: $\mathrm{IPO}^{-} \rightarrow$ weak westerly winds 
570

571

572

573

574

575

576

and small $\mathrm{PV}_{\mathrm{y}}$ over Eurasian high latitudes and North Atlantic mid-high latitudes $\rightarrow$ long-lived and westward-shifted UB with rapid growth and slow decay $\rightarrow$ upstream ECA. In contrast, $\mathrm{AMO}^{+}$influences the ECA via the following pathway: $\mathrm{AMO}^{+} \rightarrow$ weak westerly winds and small $\mathrm{PV}_{\mathrm{y}}$ over Eurasian high latitudes as well as strong zonal winds and large $\mathrm{PV}_{\mathrm{y}}$ over North Atlantic high latitudes (different from those over the North Atlantic for IPO') $\rightarrow$ long-lived UB with eastward movement, slow growth and rapid decay $\rightarrow$ downstream ECA. Thus, the role of $\mathrm{AMO}^{+}$is to cause long-lived UB with eastward movement, slow growth and rapid decay and downstream ECA through enhancing upstream zonal winds and $\mathrm{PV}_{\mathrm{y}}$, whereas the role of IPOis to cause long-lived UB occurring in the upstream side of the Ural region with rapid growth and slow decay and upstream ECA through reduced upstream zonal winds and $\mathrm{PV}_{\mathrm{y}}$. These different roles of $\mathrm{IPO}^{-}, \mathrm{AMO}^{-}$and $\mathrm{AMO}^{+}$in the longitudinal position, movement and evolution of the UB and ECA and in the change of the winter ECA from 1965-1976 to 2002-2013 are not revealed in previous studies (e.g., Luo et al. 2017b; Sung et al. 2018; B. Luo et al. 2019).

Although the NECP reanalysis data from 1950-2017 used in this paper is relatively short for sampling the IPO or AMO, the obtained results are reliable because the used data include one cycle of the AMO or at least one cycle for the IPO. However, further study is needed using long reanalysis and model data.

\section{Acknowledgements}

This manuscript was finished before 2020. This research was supported by the Chinese Academy of Sciences Strategic Priority Research Program (Grant XDA19070403), National key research and development program of China (2016YFA0601802) and the National Natural 
592 Science Foundation of China (Grant numbers: 41790473 and 41430533). A. Dai acknowledges

593 the funding support from the U.S. National Science Foundation (Grant Nos. AGS-2015780 and

594 OISE-1743738). The NCEP- NCAR reanalysis data is from https://www.esrl.noaa.gov/

$595 \mathrm{psd} /$ data/gridded/data.ncep.reanalysis, the SST data is taken from http://www.metoffice.gov.uk/

596 hadobs/hadisst/data/, the IPO and AMO indices are available from https://climexp.knmi.nl/

597 selectindex.cgi?id=someone@, somewhere and the daily NAO index is taken from https:

598 //www.cpc.noaa.gov/products/ precip/CWlink/pna/nao.shtml.

599

600

601

602

603

Booth, B. B. B., Dunstone, N. J., Halloran, P. R., Andrews, T., \& Bellouin, N., 2012: Aerosols

\section{References:}

604 implicated as a prime driver of twentieth-century North Atlantic climate variability.

Chen, X., and K.-K. Tung, 2014: Varying planetary heat sink led to global-warming slowdown and acceleration. Science, 345, 897-903, https://doi.org/10.1126/science.1254937.

Chylek, P., C. K. Folland, G. Lesins, M. K. Dubey, and M. Wang, 2009: Arctic air temperature change amplification and the Atlantic Multidecadal Oscillation. Geophys.Res. Lett., 36,

Cohen, J. L., J. C. Furtado, M. A. Barlow, V. A. Alexeev, and J. E. Cherry, 2012: Arctic warming, increasing fall snow cover and widespread boreal winter cooling, Environ. Res.

613 Cohen, J., and Coauthors, 2014: Recent Arctic amplification and extreme mid-latitude weather. Nat. Geosci., 7, 627-637, https://doi.org/10.1038/ngeo2234. 
615 Dai, A., 2013: The influence of the inter-decadal Pacific oscillation on US precipitation during 1923-2010. Clim Dyn 41:633-646. https://doi.org/10.1007/s00382-012-1446-5

617 Dai, A., J. C. Fyfe, S.-P. Xie, and X. Dai, 2015: Decadal modulation of global surface temperature by internal climate variability. Nat. Climate Change, 5, 555-559, https://doi.org/ 10.1038/nclimate2605.

Dai, A., and M. Song, 2020: Little influence of Arctic amplification on midlatitude climate. Nature Climate Change, 10, 231-237. https://doi.org/10.1038/s41558-020-0694-3.

Delworth, T. L., and M. E. Mann, 2000: Observed and simulated multidecadal variability in the Northern Hemisphere. Climate Dyn., 16,661-676,https://doi.org/10.1007/s003820000075.

Deser, D., and M. Blackmon, 1995: On the relationship between tropical and North Pacific sea surface temperature variations. J. Climate, 8,1677-1680.

Deser, C., Guo, R., and Lehner, F. 2017: The relative contributions of tropical Pacific sea surface temperatures and atmospheric internal variability to the recent global warming hiatus, Geophys. Res. Lett., 44, 7945- 7954, doi:10.1002/2017GL074273.

Diao Y., J. Li and D. Luo, 2006: A new blocking index and its application: Blocking action in the Northern Hemisphere, J. Climate, 19, 4819-4839.

Dong, B. and A. Dai, 2015: The influence of the Interdecadal Pacific Oscillation on Temperature and Precipitation over the Globe, Climate Dyn., 45, 2667. https://doi.org $\underline{10.1007 / \mathrm{s} 00382-015-2500-\mathrm{X}}$

Dong, B., A. Dai, M. Vuille, and O. Elison Timm, 2018: Asymmetric modulation of ENSO teleconnections by the Interdecadal Pacific Oscillation. J. Climate, 31:7337-7361. 
637

638

639

640

641

642

643

Hua, W., A. Dai, and M. Qin, 2018: Contributions of internal variability and external forcing to the recent Pacific decadal variations. Geophys. Res. Lett., 45, 7084-7092. https://doi.org/10.1029/2018GL079033.

Hua W., Dai A., Zhou L., Qin M., and H. Chen, 2019. An externally-forced decadal rainfall seesaw pattern over the Sahel and southeast Amazon., Geophys. Res. Lett., 46, 923-932. https://doi.org/10.1029/2018GL081406

Huang D., A. Dai, Yang B., et al., 2019: Contributions of different combinations of the IPO and AMO to recent changes in winter East Asian jets. J. Climate, 32, 1607-1625.

Huang, J. P., Y. K. Xie, X. D. Guan, D. D. Li, and F. Ji, 2017: The dynamics of the warming hiatus over the northern hemisphere, Climate Dyn., 48, 429-446, doi:10.1007/s00382016-3085-8.

Kalnay, E., and Coauthors, 1996: The NCEP/NCAR 40-Year Reanalysis project. Bull. Amer. Meteor. Soc., 77, 437-471, https://doi.org/10.1175/1520-0477(1996)077,0437: TNYRP. 2.0.CO;2.

Kaplan, A., M. A. Cane,Y.Kushnir, A. C.Clement, M. B. Blumenthal, and B. Rajagopalan, 1998: Analyses of global sea surface temperature 1856-1991. J. Geophys. Res., 103, 18 567-18 589, https://doi.org/10.1029/97JC01736.

Karl, T. R., and Coauthors, 2015: Possible artifacts of data biases in the recent global surface warming hiatus. Science, 348, 1469-1472, https://doi.org/10.1126/science.aaa5632.

Kaufmann, R. K., Kauppi, H., Mann, M. L., and J. H. Stock, 2011: Reconciling anthropogenic 
climate change with observed temperature 1998-2008. Proc. Natl Acad. Sci. USA, 108, 11790-11793.

659 Kim, H.-J., S.-W. Son, W. Moon, J.-S. Kug and J. Hwang, 2021: Subseasonal relationship between Arctic and Eurasian surface air temperature. Scientific Reports, 11, 4081, doi: 
Luo, D., Y. Yao and A. Dai, 2015: Decadal relation between European blocking and North Atlantic Oscillation during 1978-2011. Part I: Atlantic conditions. J. Atmos. Sci., 72,1152-1173.

Luo, D., Y. Xiao, Y. Yao, A. Dai, I. Simmonds, and C. L. E. Franzke, 2016a: Impact of Ural blocking on winter warm Arctic-cold Eurasian anomalies. Part I: Blocking induced amplification. J. Climate, 29, 3925-3947, https://doi.org/10.1175/JCLI-D-15-0611.1.

Luo, D., Y. Xiao, Y. Diao, A. Dai, C. L. E. Franzke and I. Simmonds, 2016b: Impact of Ural Blocking on winter Warm Arctic-Cold Eurasian anomalies. Part II: The link to the North Atlantic Oscillation. J. Climate, 29, 3949-3971, doi: 10.1175/JCLI-D-15-0612.1.

Luo, D., Y. Yao, A. Dai, I. Simmonds and L. Zhong, 2017a: Increased quasi-stationarity and persistence of winter Ural Blocking and Eurasian extreme cold events in response to Arctic warming. Part II: A theoretical explanation. J. Climate, 30, 3569-3587, doi: 10.1175/JCLI-D-16-0262.1.

Luo, D., Y. Chen, A. Dai, M. Mu, R. Zhang and I. Simmonds, 2017b: Winter Eurasian cooling linked with the Atlantic Multidecadal Oscillation, Environ. Res. Lett., 12, 125002.

Luo, D., X. Chen, A. Dai and I. Simmonds 2018: Changes in atmospheric blocking circulations linked with winter Artic warming: A new perspective. J. Climate, 31, 7661-7677

Luo, D., X. Chen and S. Feldstein, 2018b: Linear and nonlinear dynamics of North Atlantic Oscillations: A new thinking of symmetry breaking, J. Atmos. Sci., 75, 1955-1977, DOI: 10.1175/JAS- D-17-0274.1 
697

698

699

700

701

702

703

704

705

706

707

708

709

710

711

712

713

714

715

716

717

Luo, D., X. Chen, J. Overland, I. Simmonds, Wu, Y. and P. Zhang, 2019a: Weakened potential vorticity barrier linked to recent winter Arctic sea ice loss and midlatitude cold extremes. $J$. Climate, 32, 4235-4261.

Luo, D., W. Zhang, L. Zhong and A. Dai, 2019b: A nonlinear theory of atmospheric blocking: A potential vorticity gradient view. J. Atmos. Sci., 76, 2399-2427.

Marotzke, J., and P. M. Forster (2015), Forcing, feedback and internal variability in global temperature trends, Nature, 517, 565-570, doi:10.1038/nature14117.

Masato, G., B. J. Hoskins, and T. J. Woollings, 2013a: Wave-breaking characteristics of Northern Hemisphere winter blocking: A two-dimensional approach. J. Climate, 26, 4535-4549.

Masato, G., B. J. Hoskins, and T. J. Woollings, 2013b: Winter and Summer Northern Hemisphere Blocking in CMIP5 Models. J. Climate, 26, 7044-7059.

Meehl, G. A., A. Hu, J. M. Arblaster, J. Fasullo, and K. E. Trenberth, 2013: Externally forced and internally generated decadal climate variability associated with the interdecadal Pacific oscillation. J. Climate, 26, 7298-7310, https://doi.org/10.1175/ JCLI-D-1200548.1.

Meehl, G. A.,B. D. Santer, and S.-P. Xie, 2016: Contribution of the interdecadal Pacific oscillation to twentieth-century global surface temperature trends. Nat. Climate Change, 6, 1005-1008, https://doi.org/10.1038/nclimate3107.

Meehl, G. A., A. Hu, F. Castruccio and others, 2021: Atlantic and Pacific tropics connected by mutually interactive decadal-timescale processes. Nature Geoscience, 14,36-42. 
718 Mori, M., M. Watanabe, H. Shiogama, J. Inoue, and M. Kimoto, 2014: Robust Arctic sea-ice

719 influence on the frequent Eurasian cold winters in past decades. Nat. Geosci., 7, 869-873,

$720 \quad$ https://doi.org/10.1038/ngeo2277.

721 van Oldenborgh, G. J., te Raa, L. A., Dijkstra, H. A., and S. Y. Philip, 2009: Frequency- or 722 amplitude-dependent effects of the Atlantic meridional overturning on the tropical Pacific

723 Ocean, Ocean Sci., 5, 293-301, https://doi.org/10.5194/os-5-293-2009.

724 Power S, Casey T, Folland C, Colman A., and V. Mehta, 1999: Interdecadal modulation of the impact of ENSO on Australia. Climate Dyn., 15, 319-324. doi:10.1007/s003820050284

Rayner, N. A., D. E. Parker, E. B. Horton, C. K. Folland,L. V. Alexander, D. P. Rowell, E. C. Kent, and A. Kaplan, 2003:Global analyses of sea surface temperature, sea ice, and night marine air temperature since the late nineteenth century. J. Geophys. Res., 108, 4407, https://doi.org/10.1029/2002JD002670.

Rudeva, I., and I. Simmonds, 2021: Midlatitude winter extreme temperature events and connections with anomalies in the Arctic and tropics. J. Climate, 34, 3733-3749, doi: 10.1175/JCLI-D-20-0371.1.

Sung, M.-K., S.-H. Kim, B.-M. Kim and Y.-S. Choi, 2018: Interdecadal variability of the Warm Arctic and Cold Eurasia Pattern and its North Atlantic origin. J. Climate, 31, 5793-5810, doi: 10.1175/JCLI-D-17-0562.1.

Steinman B. A., M. E. Mann and S. K. Miller, 2015: Atlantic and Pacific multidecadal oscillations and Northern Hemisphere temperatures. Science, 347, 988-991. doi:10.1126/science. 1257856 
739 Tibaldi, S., and F. Molteni, 1990: On the operational predictability of blocking. Tellus, 42A, 343-365, doi:10.1034/j.1600-0870.1990.t01-2-00003.x.

741

Trenberth, K. E., and D. J. Shea, 2006: Atlantic hurricanes and natural variability in 2005. Geophys. Res. Lett., 33, L12704, https://doi.org/10.1029/2006GL026894.

Trenberth K. E, and J. T, Fasullo, 2013: An apparent hiatus in global warming? Earth's Future 1, 19-32. https ://doi.org/10.1002/2013E F000165.

Trenberth, K. E., 2015: Has there been a hiatus. Science, 349, 691-692. https ://doi.org/ 10.1126/scien ce.aac92 25.

Tyrlis, E, Bader, J, Manzini, E, Ukita, J, Nakamura, H, Matei, D., 2020: On the role of Ural Blocking in driving the Warm Arctic-Cold Central Eurasia pattern. Quart. J. R. Meteorol. Soc., 146, 2138- 2153。

Tyrlis E, Bader J, Manzini E and D. Matei, 2021: Reconciling different methods of high-latitude blocking detection. Quart. J. Roy. Meteor. Soc. 147: 1070-1096 doi: 10.1002/qj.3960.

Wyatt, M.G., Kravtsov, S. and A. A. Tsonis, 2012: Atlantic Multidecadal Oscillation and Northern Hemisphere's climate variability. Climate Dyn., 38: 929-949.

Wilks, D. S., 2011, Statistical methods in the atmospheric sciences, $3^{\text {rd }}$ Edition, Academic Press, Oxford.

Woollings, T. J., B. J. Hoskins, P. Blackburn, and P. Berrisford, 2008: A new Rossby wave-breaking interpretation of the North Atlantic Oscillation. J. Atmos. Sci., 65, 609-626, . doi:10.1175/2007JAS2347.1. 
760 Yao, Y., D. Luo, A. Dai, and I. Simmonds, 2017: Increased quasi stationarity and persistence

761 of winter Ural blocking and Eurasian extreme cold events in response to Arctic warming.

762 Part I: Insights from observational analyses. J. Climate, 30, 3549-3568,

763 Wei M, F. Qiao and J. Deng, 2015: A quantitative definition of global warming hiatus and

76450 -Year prediction of global-mean surface temperature. J Atmos Sci., 72:3281-3289.

765 Zhang, R., and T. L. Delworth, 2007: Impact of the Atlantic multidecadal oscillation on North

766 Pacific climate variability. Geophys. Res. Lett., 34, L23708, https://doi.org/10.1029/2007

767 GL031601

Zhang, W., and D. Luo, 2020: A Nonlinear theory of atmospheric blocking: An application to Greenland blocking changes linked to winter Arctic sea ice loss. J. Atmos. Sci., 77, $723-751$.

771

772

773

774

775

776

777

778

779

780

781

782

783

784

785

786

787

788

789

790

791 

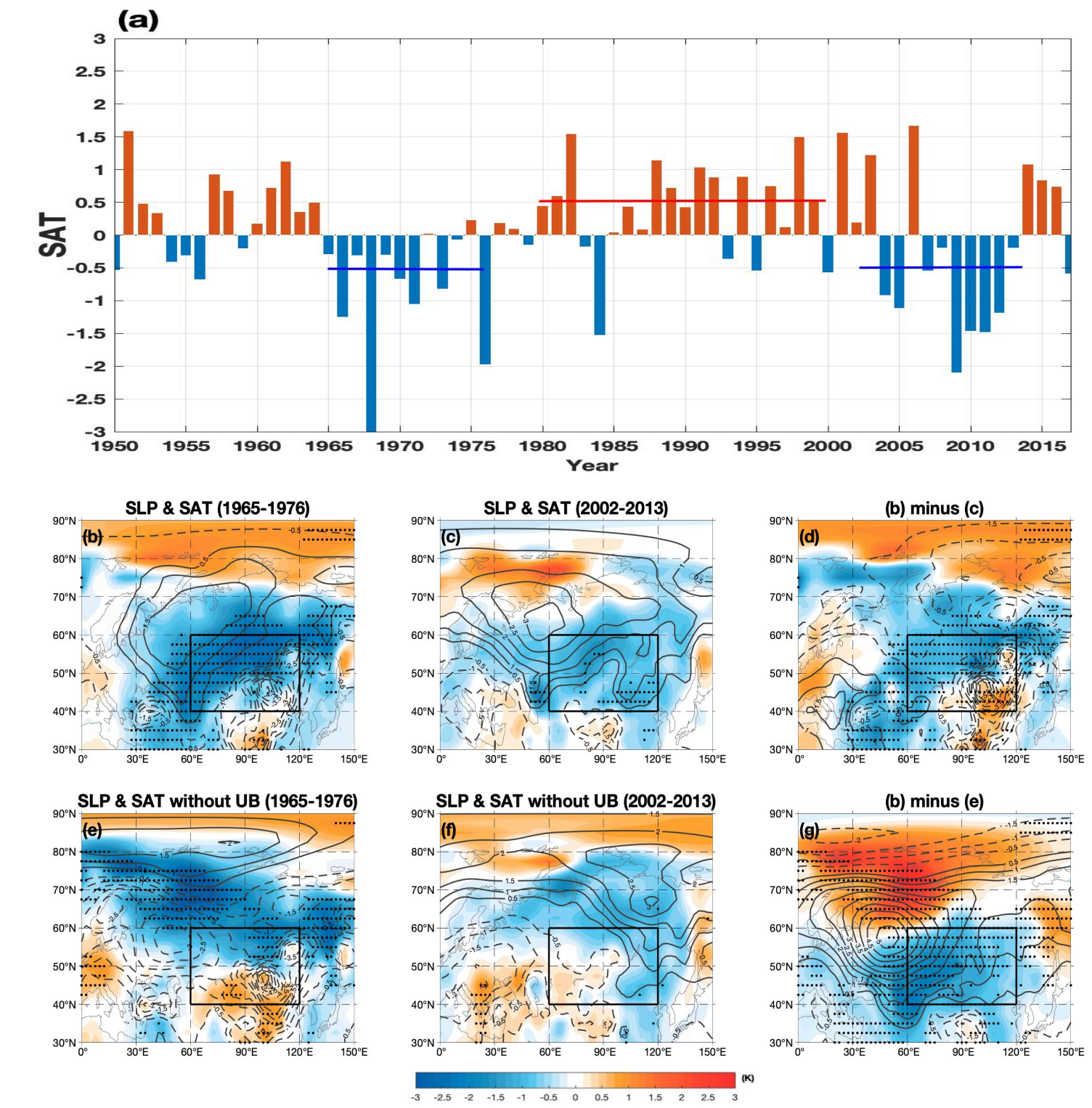

Figure 1. (a) Time series of DJF-mean surface air temperature (SAT) anomalies averaged over central Eurasia $\left(60^{\circ}-120^{\circ} \mathrm{E}, 40^{\circ}-60^{\circ} \mathrm{N}\right)$, with the red line denoting the $1980-2000$ period, and the blue line marking the 1965-1976 and 2002-2013 periods. (b, c, d, e, f, g) DJF-mean sea surface pressure (SLP) (contours; contour interval $(\mathrm{CI})=0.5 \mathrm{hPa}$ ) and SAT (color shading in $\mathrm{K}$ ) anomalies averaged during (b, e) 1965-1976 and (c, f) 2002-2013 for UB events (b, c) included and (e, f) excluded (blocking days from lag -10 to 10 days are excluded, lag 0 denotes the day of the UB peak) as well as (d) b minus c and (g) b minus e differences. The dot represents the areas of the SAT anomaly being significant at the 95\% level based on a two-sided Student t-test. 


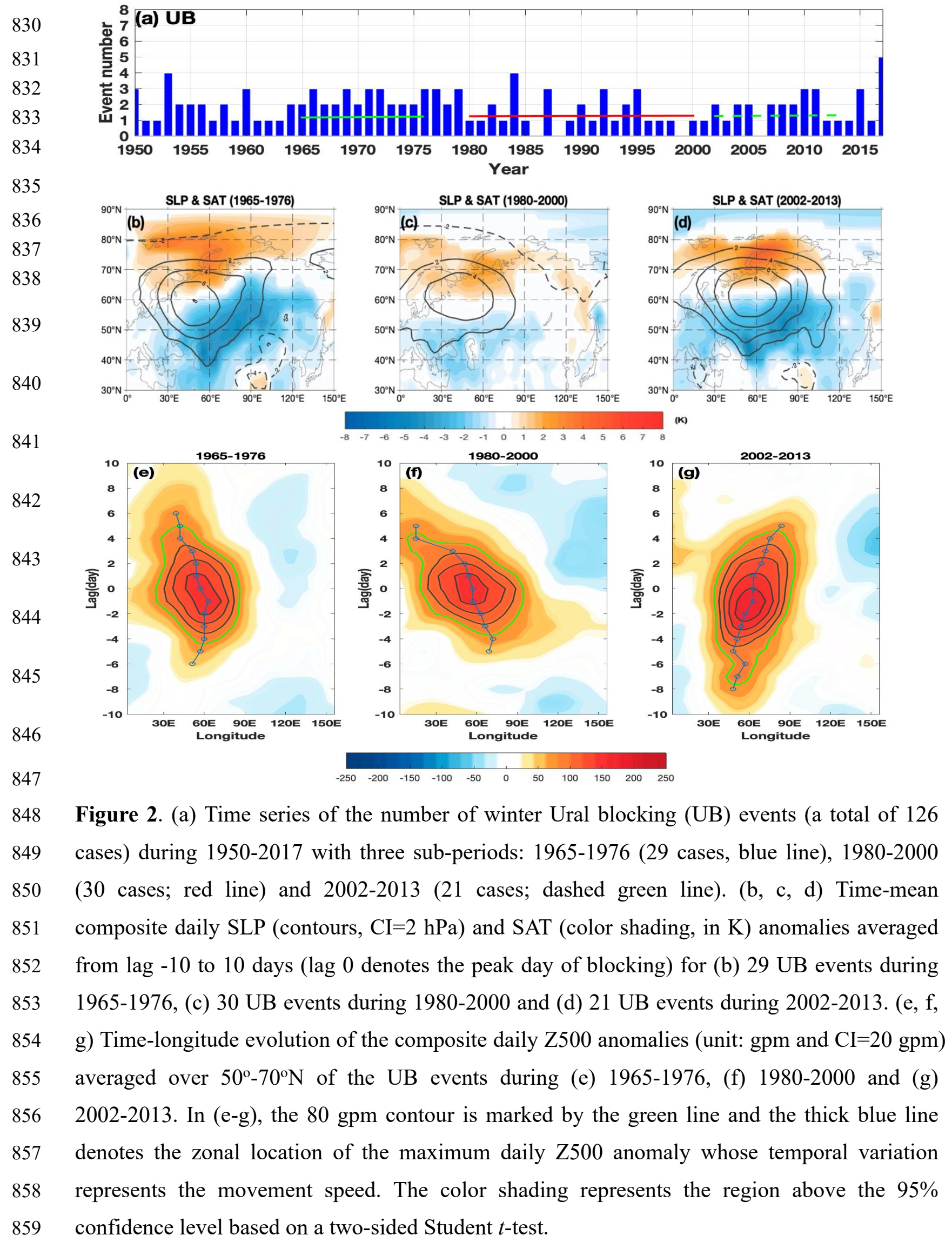



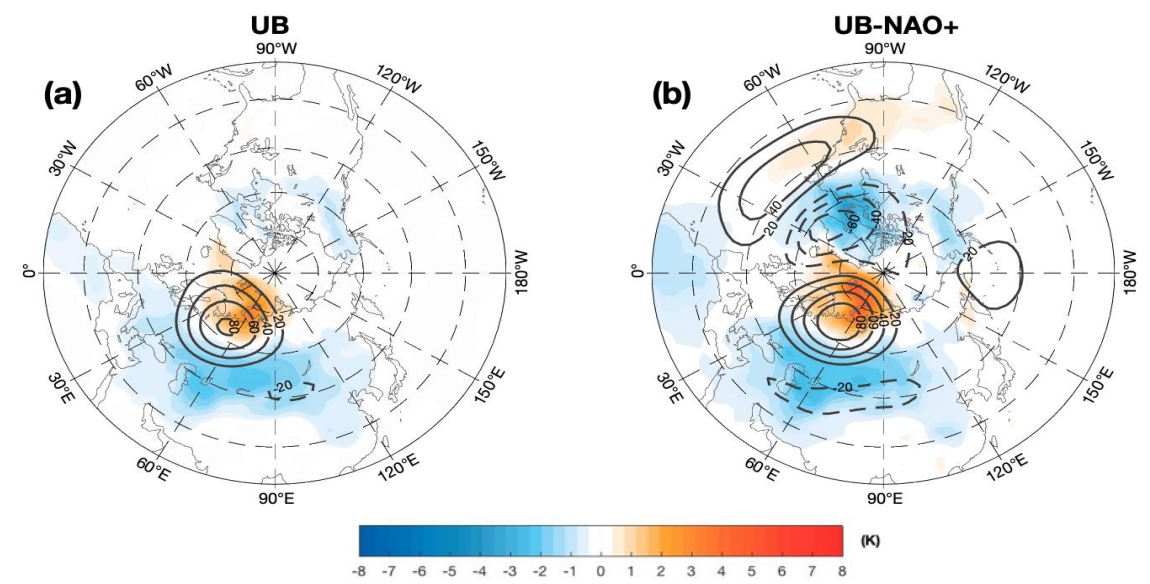

1965-1976 minus 2002-2013

UB

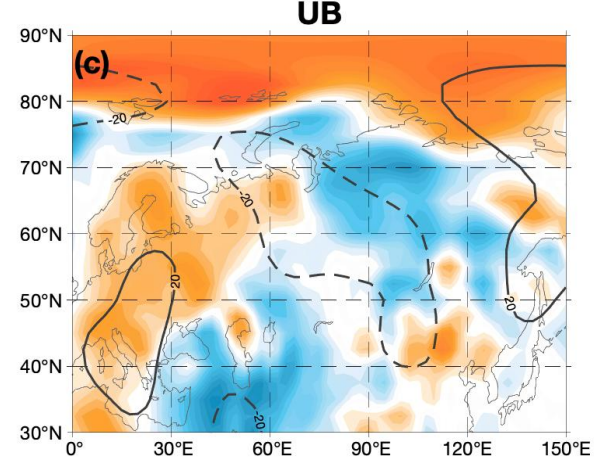

1965-1976 minus 2002-2013
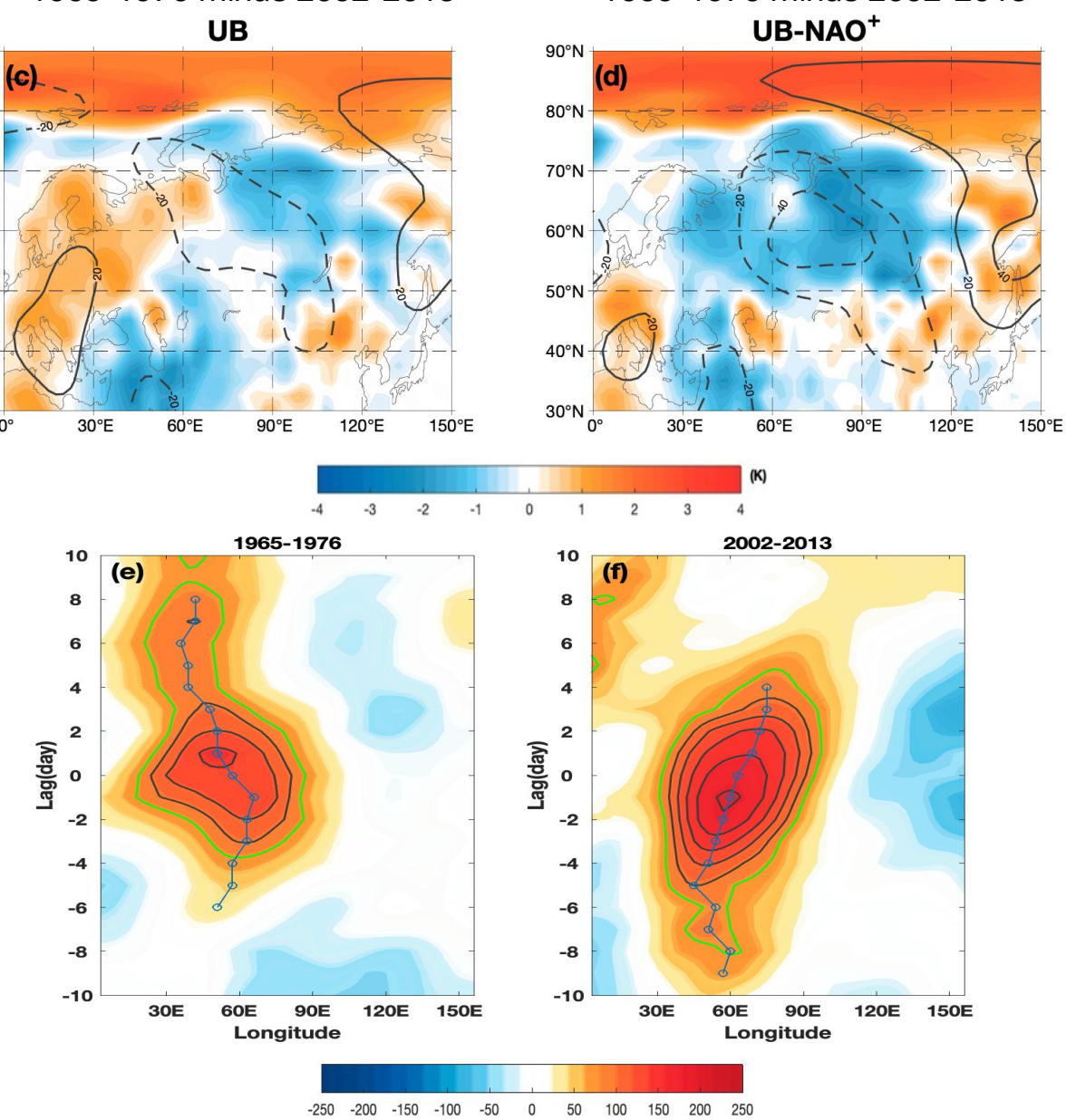

Figure 3. Time-mean composite daily $500-\mathrm{hPa}$ geopotential height (Z500) (contours, CI=20 gpm) and SAT (color shading, unit: K) anomalies averaged from lag -10 to 10 days (lag 0 denotes the peak day of blocking) for (a) UB and (b) UB-NAO ${ }^{+}$events during 1950-2017. (c, d) 1965-1976 minus 2002-2013 differences of time-mean Z500 and SAT anomalies for (c) UB and (d) $\mathrm{UB}_{-} \mathrm{NAO}^{+}$events, where the color shading represents the region above the $95 \%$ confidence level based on a two-sided Student t-test. (e, f) Time-longitude evolution of composite daily Z500 anomalies (unit: gpm and $\mathrm{CI}=20 \mathrm{gpm}$ ) averaged over $50^{\circ}-70^{\circ} \mathrm{N}$ of $\mathrm{UB}^{-N A O}{ }^{+}$events during (e) 1965-1976 and (f) 2002-2013. The 80 gpm contour is marked by the green line and the thick blue line with dot denotes the zonal location of the maximum daily Z500 anomaly and its temporal variation represents the movement speed. 
903

904

905

906

907

908

909

910

911

912

913

914

915

916

917

918

919

920

921

922

923

924

925

926

927

928
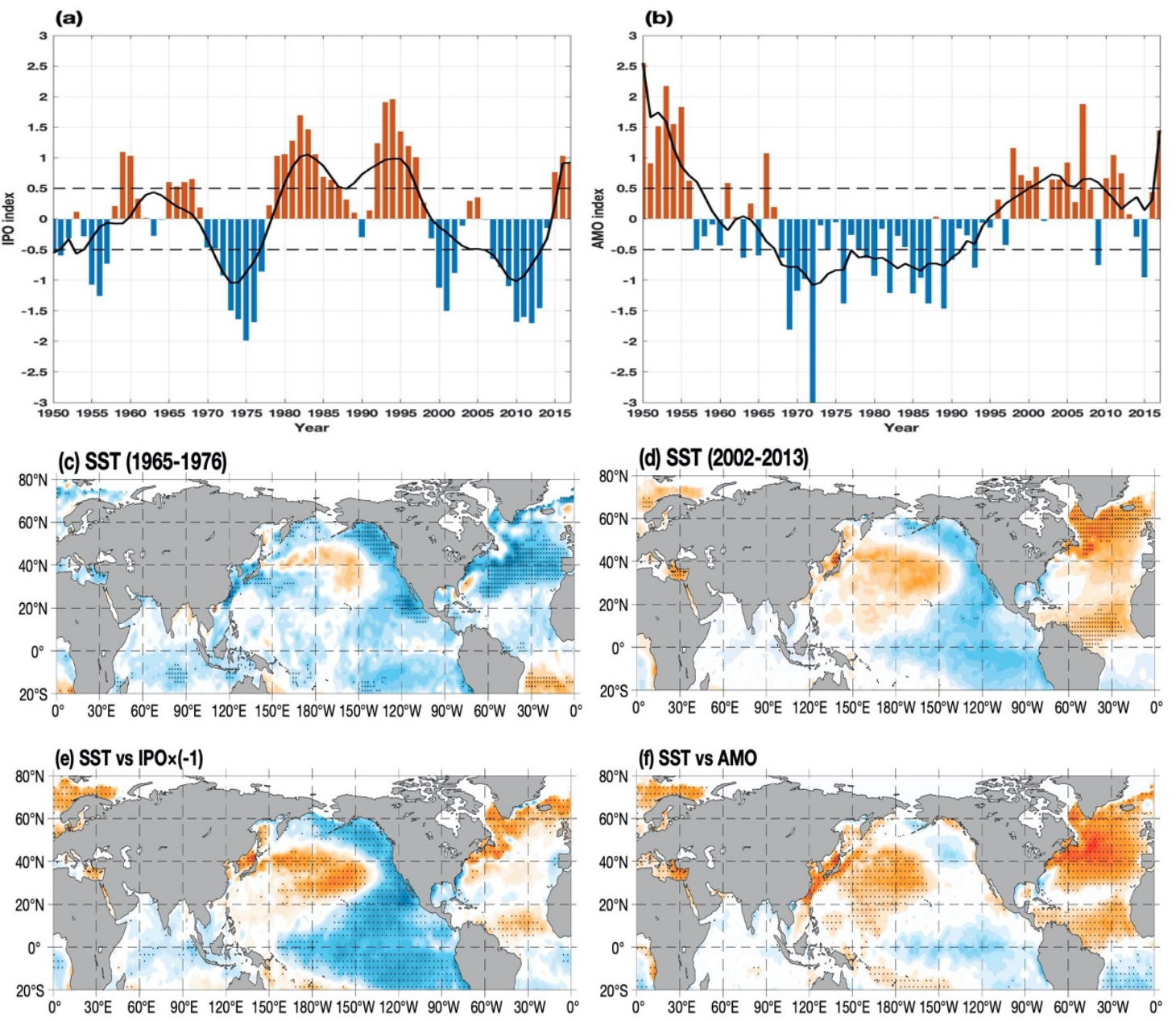

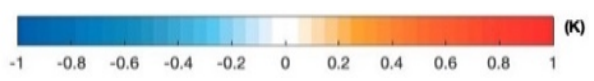

Figure 4. (a, b) Time series of normalized DJF-mean (a) Interdecadal Pacific Oscillation (IPO) and (b) Atlantic Multidecadal Oscillation (AMO) indices during 1950-2017, where the black solid line represents a 9-year moving average. (c, d) Time-mean winter SST anomalies during (c) 1965-1976 and (d) 2002-2013. (e, f) regressed DJF-mean SST (color shading, in K per unit index) against the normalized (a) DJF-mean IPO index (multiplied by -1.0) and (b) AMO index time series with a 9-year moving average. In panels e-f, the dot in the color shading region represents the region above the 95\% confidence level based on a two-sided Student t-test. 

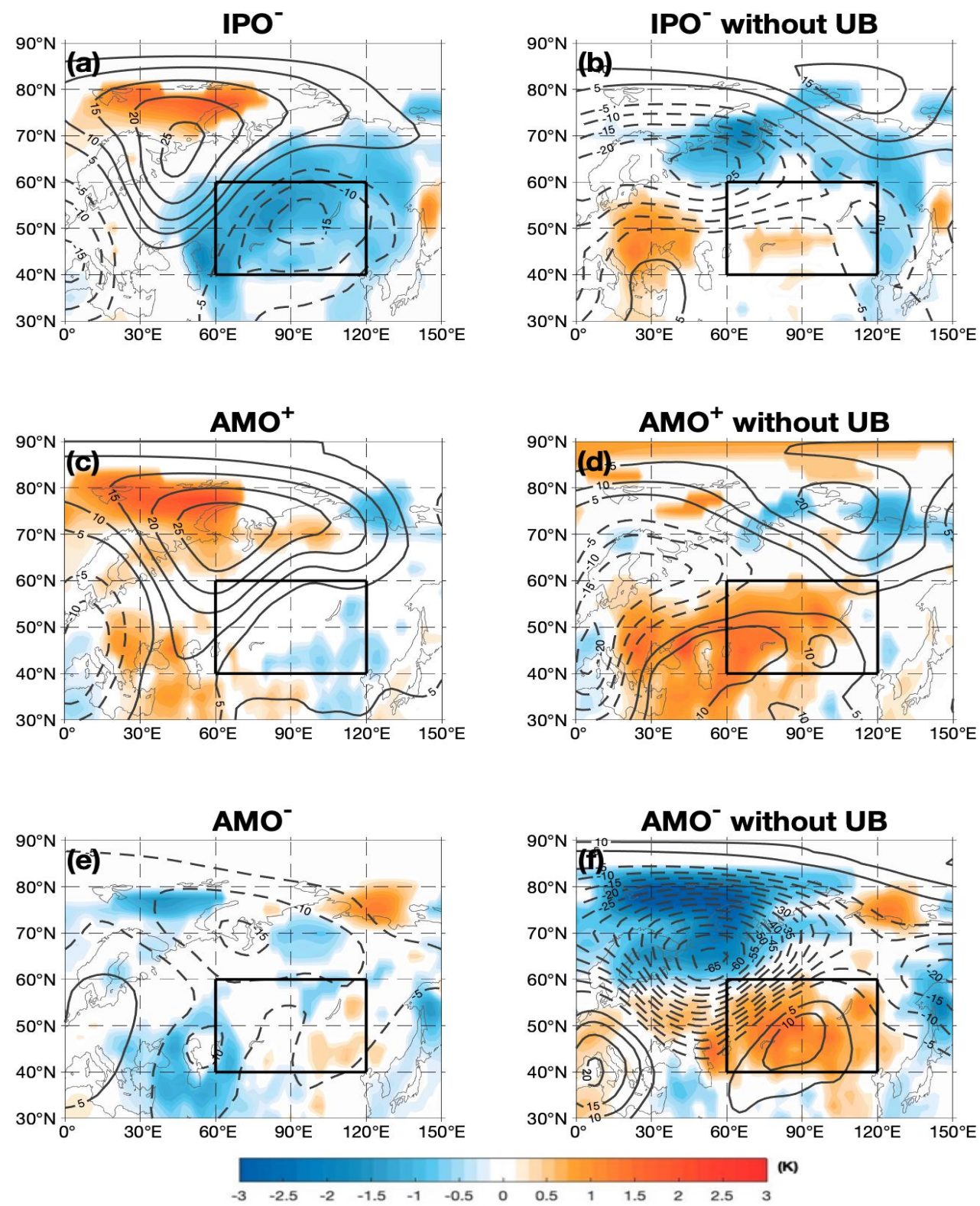

Figure 5. Composite DJF-mean Z500 (contours, unit: gpm) and SAT (color shading) anomalies in $(\mathrm{a}, \mathrm{b}) \mathrm{IPO}^{-},(\mathrm{c}, \mathrm{d}) \mathrm{AMO}^{+}$and $(\mathrm{e}, \mathrm{f}) \mathrm{AMO}^{-}$winters during 1950-2017 based on the $0.5 \mathrm{STD}$ threshold value definition of 9-year smoothed IPO and AMO indices for days (a, c, e) with and $(b, d, f)$ without UB events (the case without UB represents that blocking days from lag -10 to 10 are removed for each UB event in winter). The composite field with UB events during IPO$\left(\mathrm{AMO}^{-}\right.$or $\left.\mathrm{AMO}^{+}\right)$is referred to as the $\mathrm{IPO}^{-}\left(\mathrm{AMO}^{-}\right.$or $\left.\mathrm{AMO}^{+}\right)$case, whereas the composite field without UB events (blocking days from lag -10 to 10 days are removed) during $\mathrm{IPO}^{-}\left(\mathrm{AMO}^{-}\right.$or $\left.\mathrm{AMO}^{+}\right)$is referred to as the $\mathrm{IPO}^{-}\left(\mathrm{AMO}^{-}\right.$or $\left.\mathrm{AMO}^{+}\right)$without $\mathrm{UB}$ case. Color shading represents the areas being significant at the $95 \%$ level based on a two-sided Student t-test. Black box represents Siberia 
967

968

969

970

971

972

973

974

975

976

977

978

979

980

981

982

983

984

985

986

987

988

989

990

991

992

993

994

995

996

997

998

999

1000

1001

1002

1003

1004

1005

1006

(1)
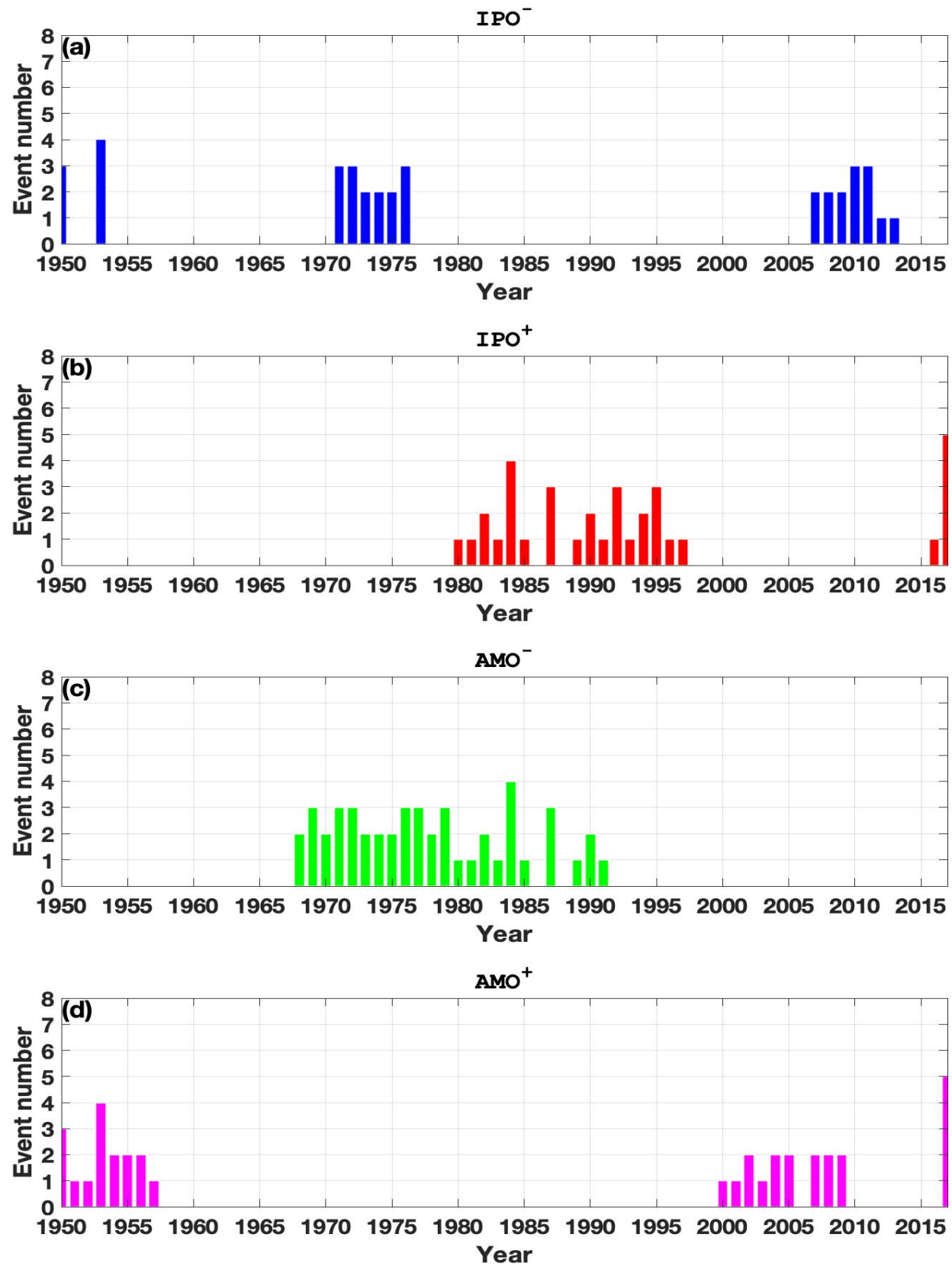

Figure 6. (a, b, c, d) Time series of winter UB events during (a) $\mathrm{IPO}^{-}$, (b) $\mathrm{IPO}^{+}$, (c) $\mathrm{AMO}^{-}$and (d) $\mathrm{AMO}^{+}$based on the $0.5 \mathrm{STD}$ definitions of the normalized 9-year moving averaged IPO and AMO indices during 1950-2017. 

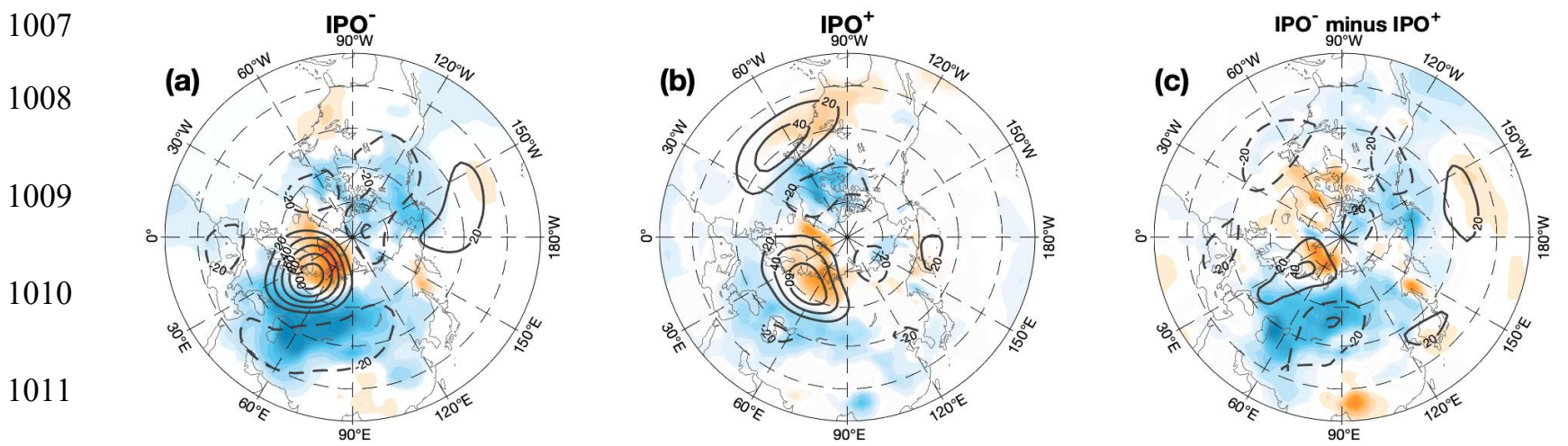

1012

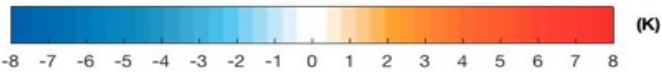

1013

1014

1015

1016

1017

1018

1019
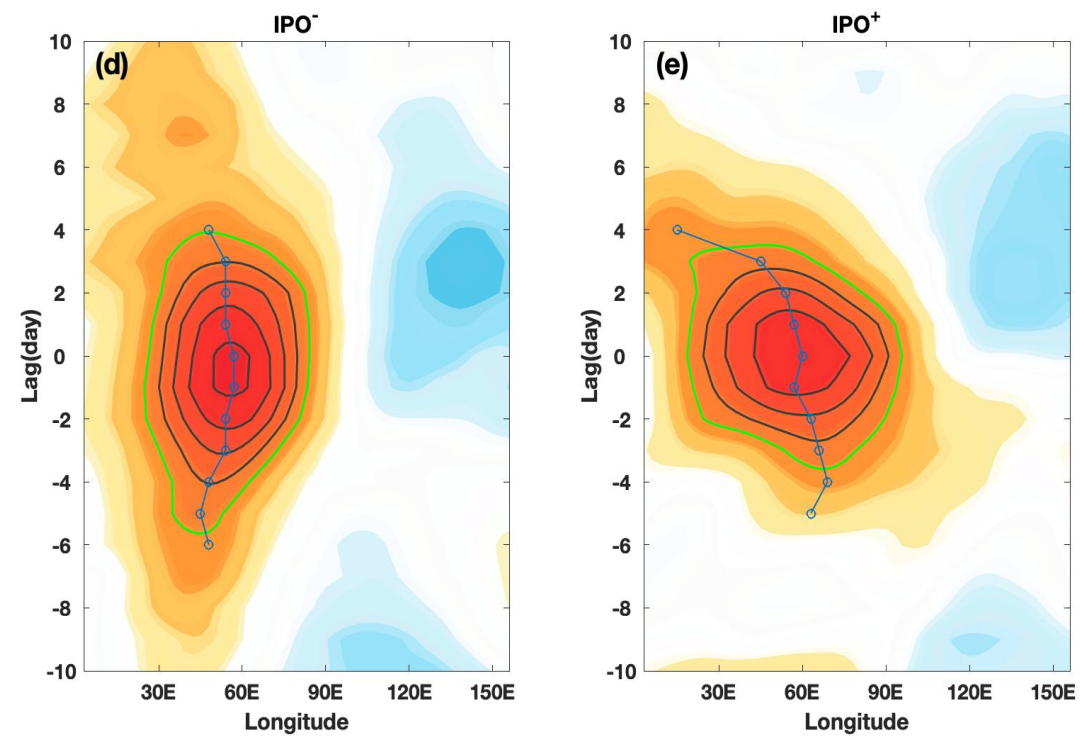

1020

1021

$\begin{array}{lllllllllll}-250 & -200 & -150 & -100 & -50 & 0 & 50 & 100 & 150 & 200 & 250\end{array}$

1022 Figure 7. Time-mean composite daily Z500 (contour; CI=20 gpm) and SAT (color shading)

1023 anomalies averaged from lag -10 to 10 days (lag 0 denotes the peak day of blocking) of $36 \mathrm{UB}$

1024 events during (a) IPO- (16 cases), (b) 34 UB events during IPO $^{+}$(19 cases) and (c) IPO $^{-}$minus

$1025 \mathrm{IPO}^{+}$difference based on the $0.5 \mathrm{STD}$ definition of the 9-year moving averaged IPO index. (d, 1026 e) time-longitude evolution of composite daily Z500 anomalies (contours; the green line represents $80 \mathrm{gpm}$ and $\mathrm{CI}=20 \mathrm{gpm}$ ) averaged over the latitudes $50^{\circ}-70^{\circ} \mathrm{N}$ of $\mathrm{UB}$ events during (d) $\mathrm{IPO}^{-}$and (e) $\mathrm{IPO}^{+}$. In panels a-b, the color shading represents the region above the $95 \%$ confidence level based on a two-sided Student t-test. In panels c-d, the thick blue line denotes the zonal location of the maximum daily Z500 anomaly and its temporal variation represents the movement speed. 

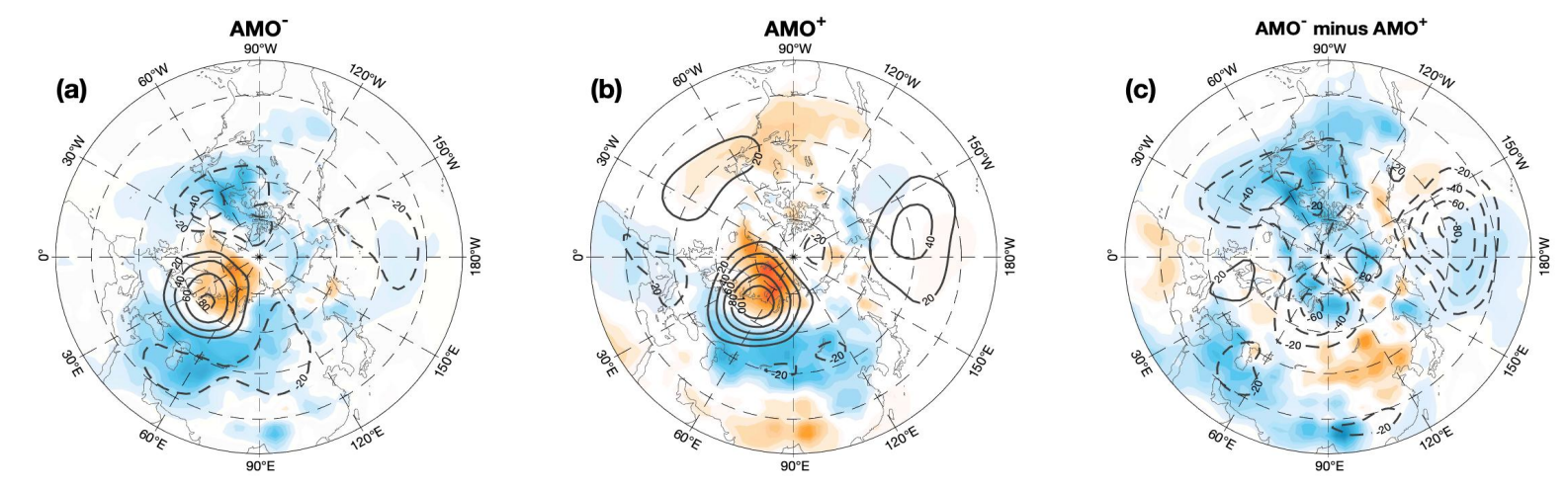

1038

1039

1040

1041

1042

1043

1044

1045
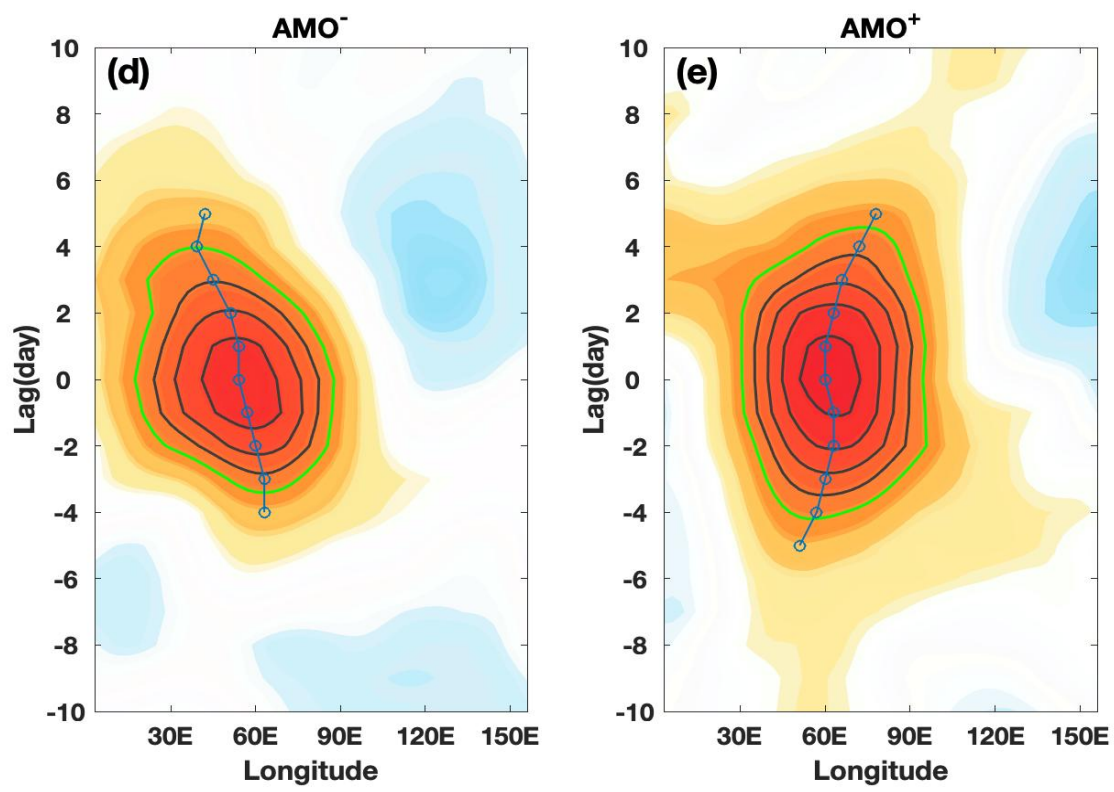

1046

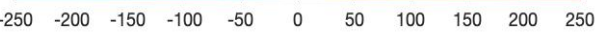

1047 Figure 8. Time-mean composite daily Z500 (contours, CI=20 gpm) and SAT (color shading, in

$1048 \mathrm{~K}$ ) anomalies averaged from lag -10 to 10 days (lag 0 denotes the peak day of blocking) for the

1049 (a) $43 \mathrm{UB}$ events during $\mathrm{AMO}^{-}$(22 cases), (b) $33 \mathrm{UB}$ events during $\mathrm{AMO}^{+}$(18 cases) and (c)

$1050 \mathrm{AMO}^{-}$minus $\mathrm{AMO}^{+}$difference based on the $0.5 \mathrm{STD}$ definition of the 9-year moving averaged

1051 AMO index from 1950-2017. (d, e) Time-longitude evolution of composite daily Z500 1052 anomalies (unit: gpm, the green line represents the 80 gpm contour and $\mathrm{CI}=20 \mathrm{gpm}$ ) averaged 1053 over the latitudes $50^{\circ}-70^{\circ} \mathrm{N}$ of the UB events during (d) $\mathrm{AMO}^{-}$and (e) $\mathrm{AMO}^{+}$. In panels a-b, the 1054 color shading represents the region with SAT anomalies above the $95 \%$ confidence level based on a two-sided Student t-test. In panels d-e, the thick blue line denotes the zonal location of the maximum daily Z500 anomaly and its temporal variation represents the movement speed. 

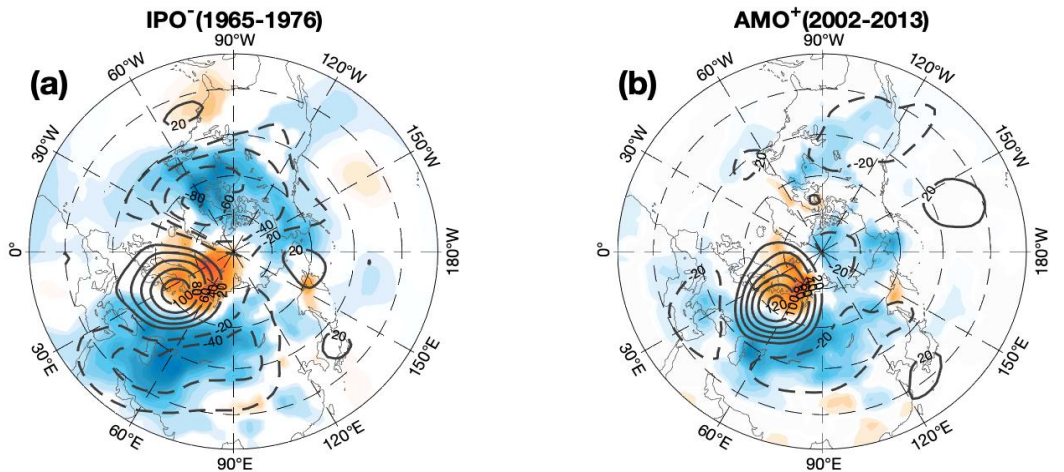

1063

1064

1065

1066

1067

1068

1069

1070

1071

1072

1073

1074

1075

1076
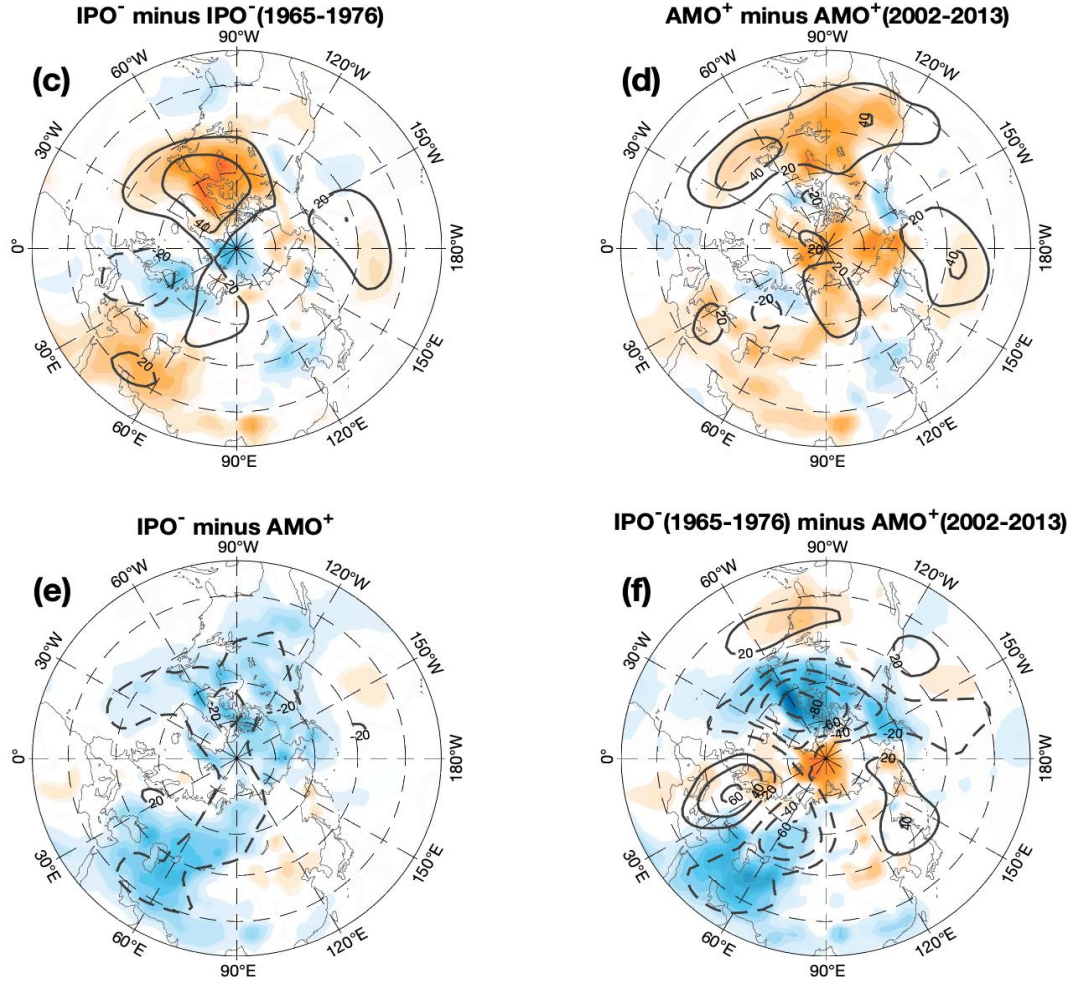

1077

Figure 9. Time-mean composite daily Z500 (contours, CI=20 gpm) and SAT (color shading, in

1078

1079

1080

$\mathrm{K}$ ) anomalies averaged from lag -10 to 10 days (lag 0 denotes the peak day of blocking) of UB events for IPO- during (a) 1965-1976 (20 UB events) and (b) $\mathrm{AMO}^{+}$during 2002-2013 (21 UB events) as well as (c) IPO- during 1950-2017 minus IPO- (1965-1976), (d) $\mathrm{AMO}^{+}$during 1081 1950-2017 minus $\mathrm{AMO}^{+}$(2002-2013), (e) IPO- minus $\mathrm{AMO}^{+}$during 1950-2017 and (f) IPO-

1082 (1965-1976) minus $\mathrm{AMO}^{+}(2002-2013)$ differences based on 9-year smoothed IPO and AMO 1083 indices. The color shading represents the region above the $95 \%$ confidence level based on a 1084 two-sided Student t-test. 

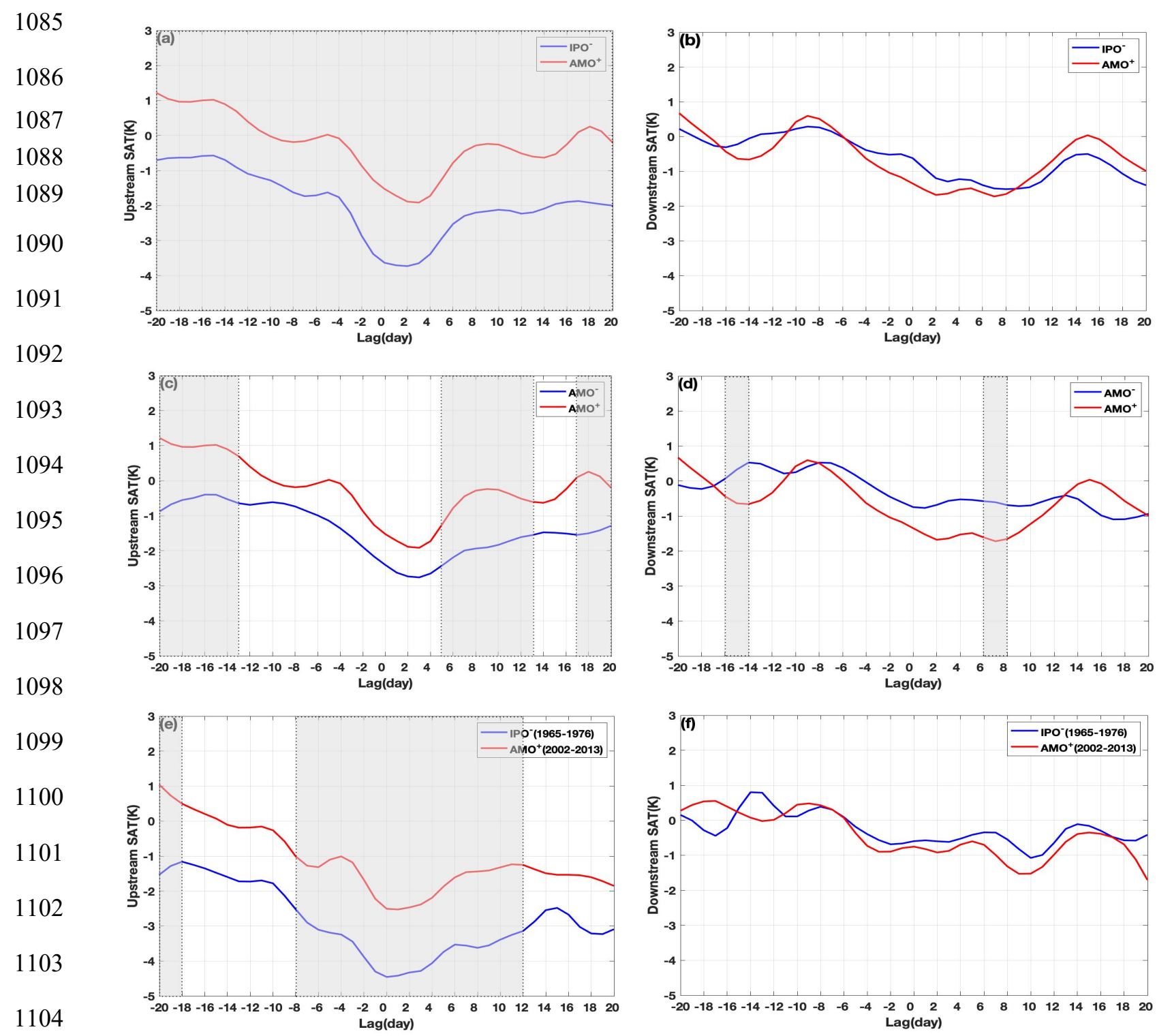

1105

Figure 10. Time evolution of composite daily SAT anomalies averaged over (a, c, e) upstream 1106 $\left(30^{\circ}-50^{\circ} \mathrm{N}, 30^{\circ}-70^{\circ} \mathrm{E}\right)$ and $(\mathrm{b}, \mathrm{d}, \mathrm{f})$ downstream $\left(30^{\circ}-50^{\circ} \mathrm{N}, 90^{\circ}-130^{\circ} \mathrm{E}\right)$ regions, referred to as upstream and downstream SAT anomalies, during the UB life cycle from lag -20 to 20 days 1108 (lag 0 denotes the peak day) for UB events during $\mathrm{IPO}^{-}$(blue line), $\mathrm{AMO}^{-}$(blue line) and $\mathrm{AMO}^{+}$(red line) during (a, b, c, d)1950-2018 and (e, f) 1965-1976 and 2002-2013. The gray shading represents the difference of two curves being significant at the $95 \%$ confidence level 1111 for a Monte-Carlo test based on a 5000 times simulation. 

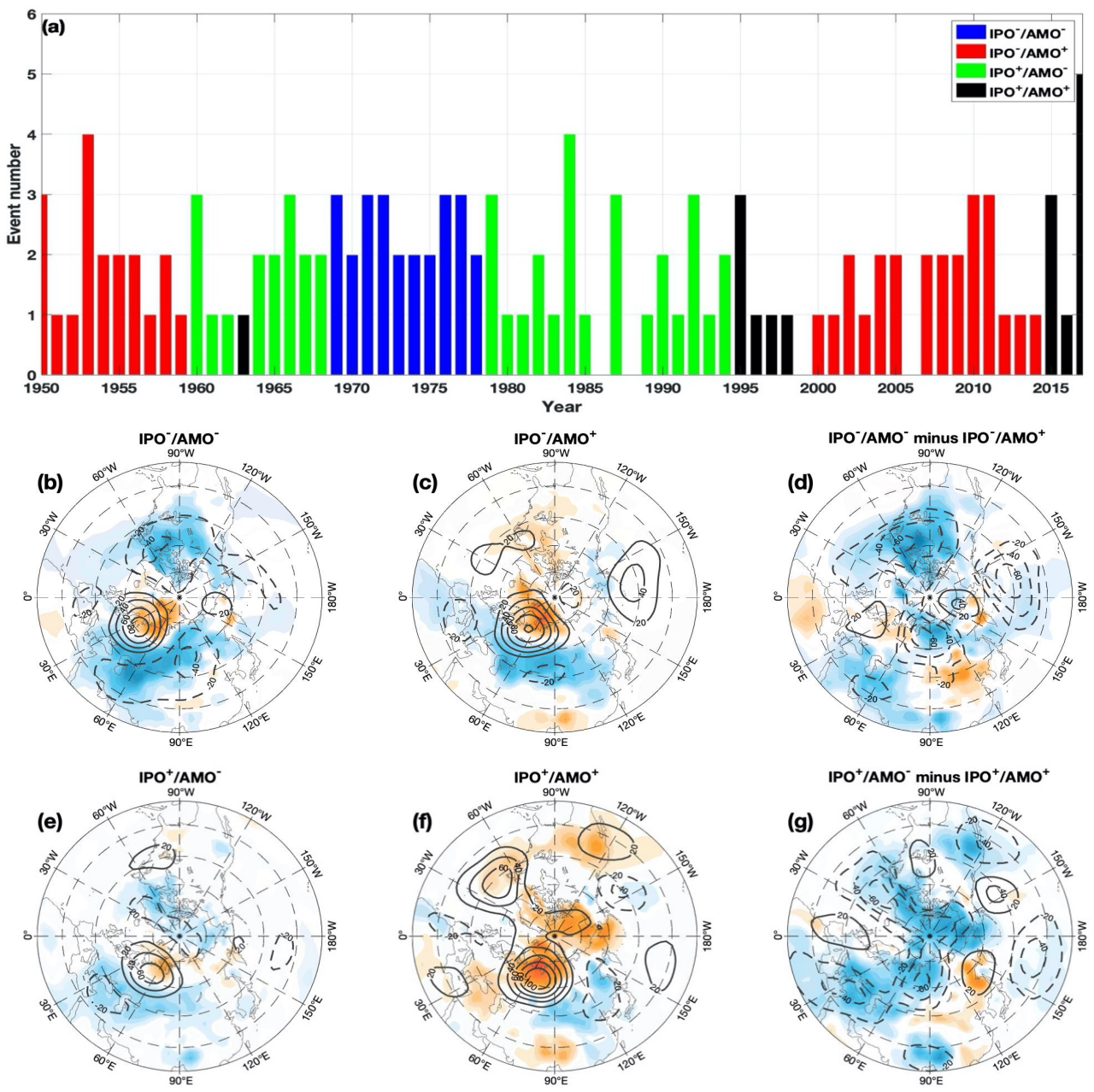

1131

1132

Figure 11. (a) Time series of winter $\mathrm{UB}^{\mathrm{a}}$ events in winter for $\mathrm{IPO}^{-} / \mathrm{AMO}^{-}$(10 cases, blue), $\mathrm{IPO}^{-} / \mathrm{AMO}^{+}$(24 cases, red), $\mathrm{IPO}^{+} / \mathrm{AMO}^{-}$(22 cases, green), and (black) $\mathrm{IPO}^{+} / \mathrm{AMO}^{+}(8$ cases, black) combinations based on 9-year smoothed IPO and AMO indices. (b, c, d, e) Time-mean Z500 (contour, $\mathrm{CI}=20 \mathrm{gpm}$ ) and SAT (color shading) anomalies averaged from lag -10 to 10 days (lag 0 denotes the peak day of blocking) of 25, 43, 42 and 16 UB events during (b) $\mathrm{IPO}^{-} / \mathrm{AMO}^{-}$, (c) $\mathrm{IPO}^{-} / \mathrm{AMO}^{+}$, (d) $\mathrm{IPO}^{+} / \mathrm{AMO}^{-}$, and (e) $\mathrm{IPO}^{+} / \mathrm{AMO}^{+}$combinations. In panels b-e, the color shading represents the region above the $95 \%$ confidence level based on a two-sided Student t-test.

1140 

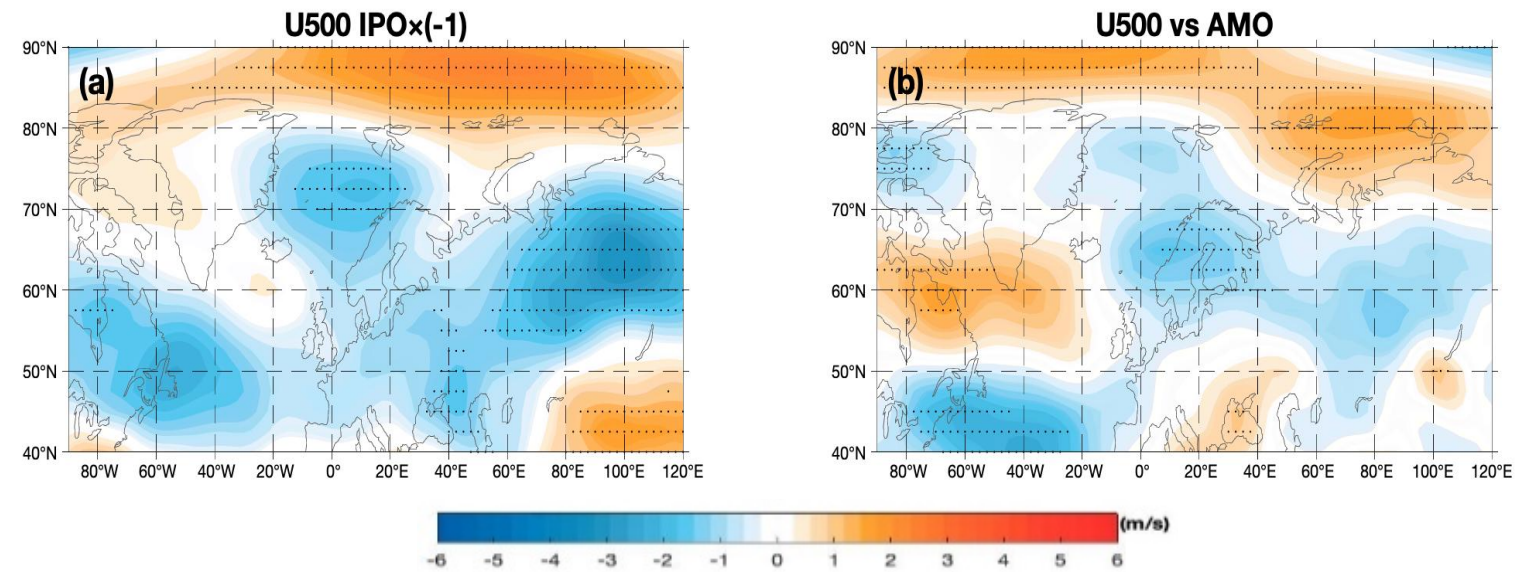

Ox(-1)
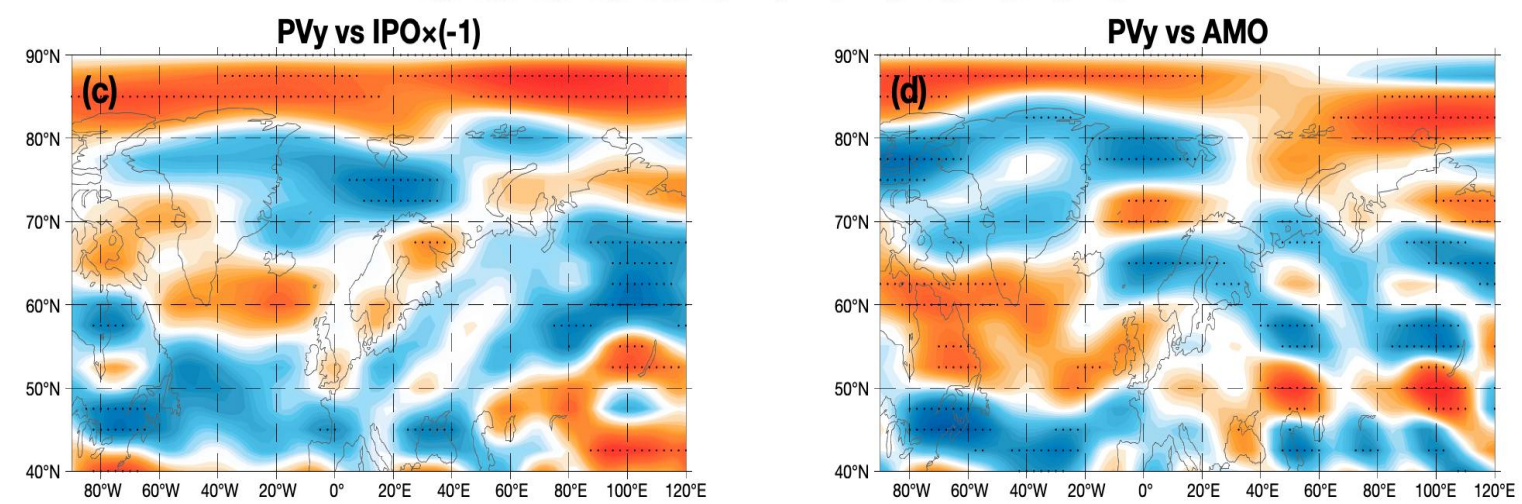

1158

1160

1161

1162

1163

1164
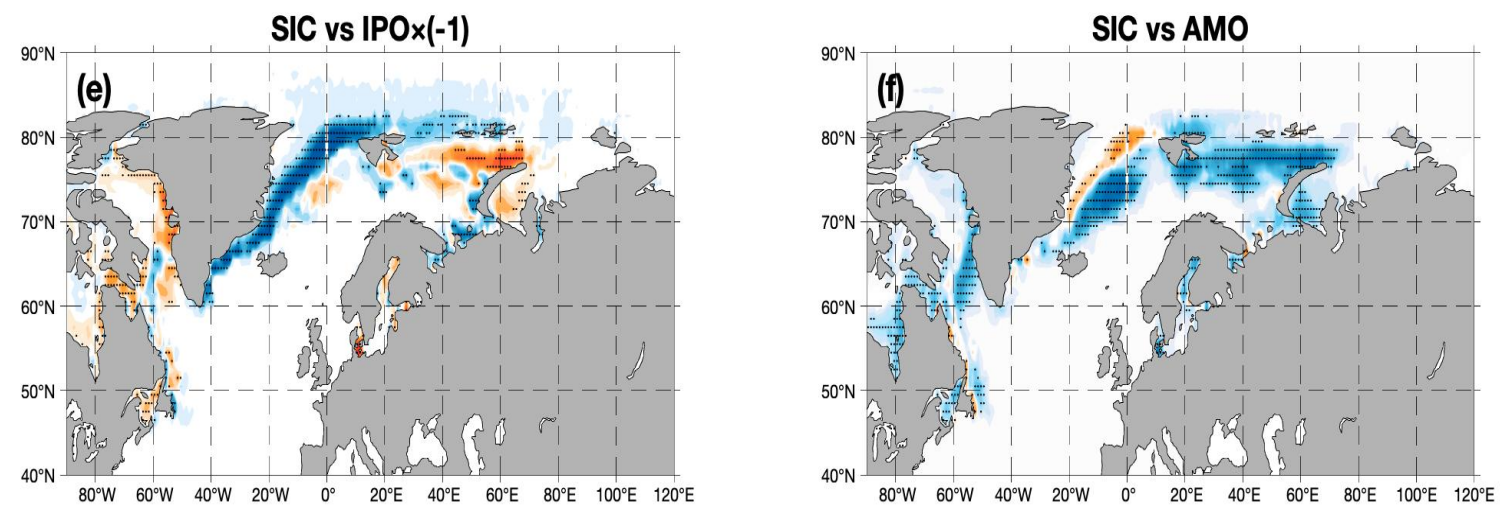

1165 Figure 12. DJF-mean ( $a, b)$ U500, $(c, d)$ non-dimensional $P V_{y}$ for UB events removed and (e, f)

1166 SIC anomalies regressed onto the time series of normalized DJF-mean (a, c, e) IPO index

1167 (multiplied by -1.0) and (b, d, f) AMO index with a 9-year smoothing. The dot represents the

1168 region above the 95\% confidence level for a two-sided Student t-test. 


\section{Figures}
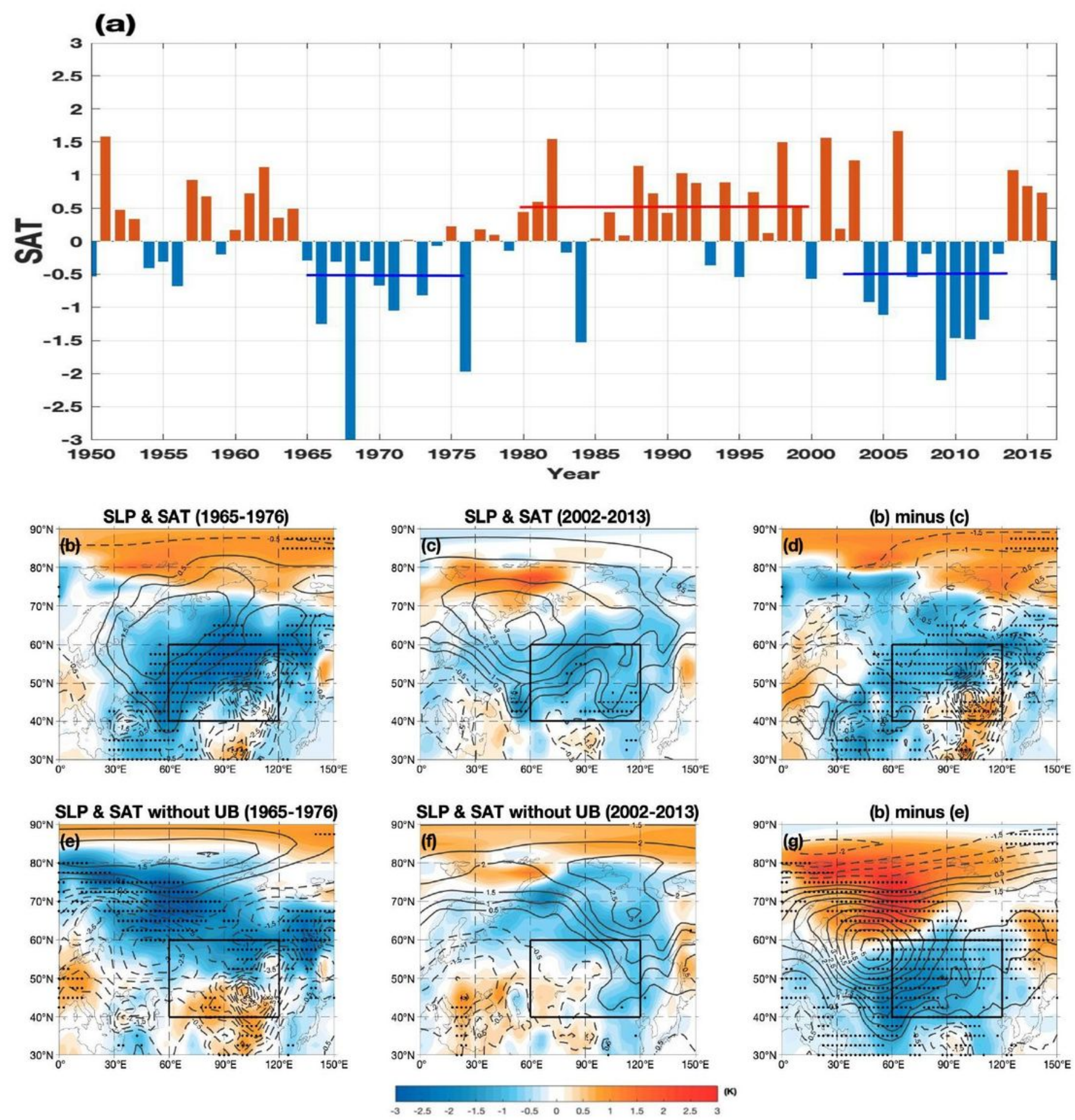

(b) minus (e)

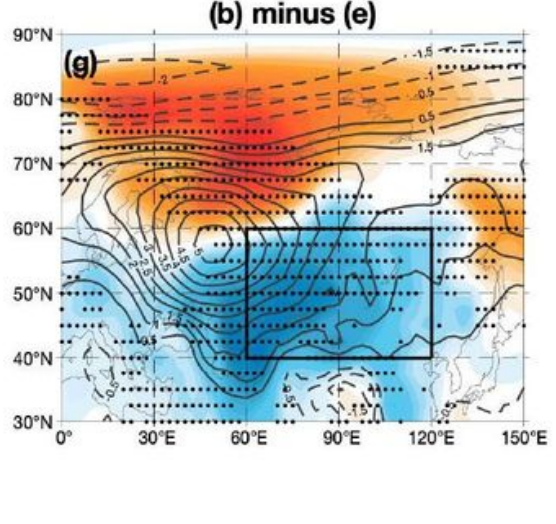

\section{Figure 1}

(a) Time series of DJF-mean surface air temperature (SAT) anomalies averaged over central Eurasia (60o-120oE, 40o-60oN), with the red line denoting the 1980-2000 period, and the blue line marking the 1965-1976 and 2002-2013 periods. (b, c, d, e, f, g) DJF-mean sea surface pressure (SLP) (contours; contour interval $(\mathrm{Cl})=0.5 \mathrm{hPa}$ ) and SAT (color shading in $\mathrm{K}$ ) anomalies averaged during (b, e) 1965-1976 
and (c, f) 2002-2013 for UB events (b, c) included and (e, f) excluded (blocking days from lag -10 to 10 days are excluded, lag 0 denotes the day of the UB peak) as well as (d) b minus $c$ and (g) b minus e differences. The dot represents the areas of the SAT anomaly being significant at the $95 \%$ level based on a two-sided Student t-test. Black box represents central Eurasia.
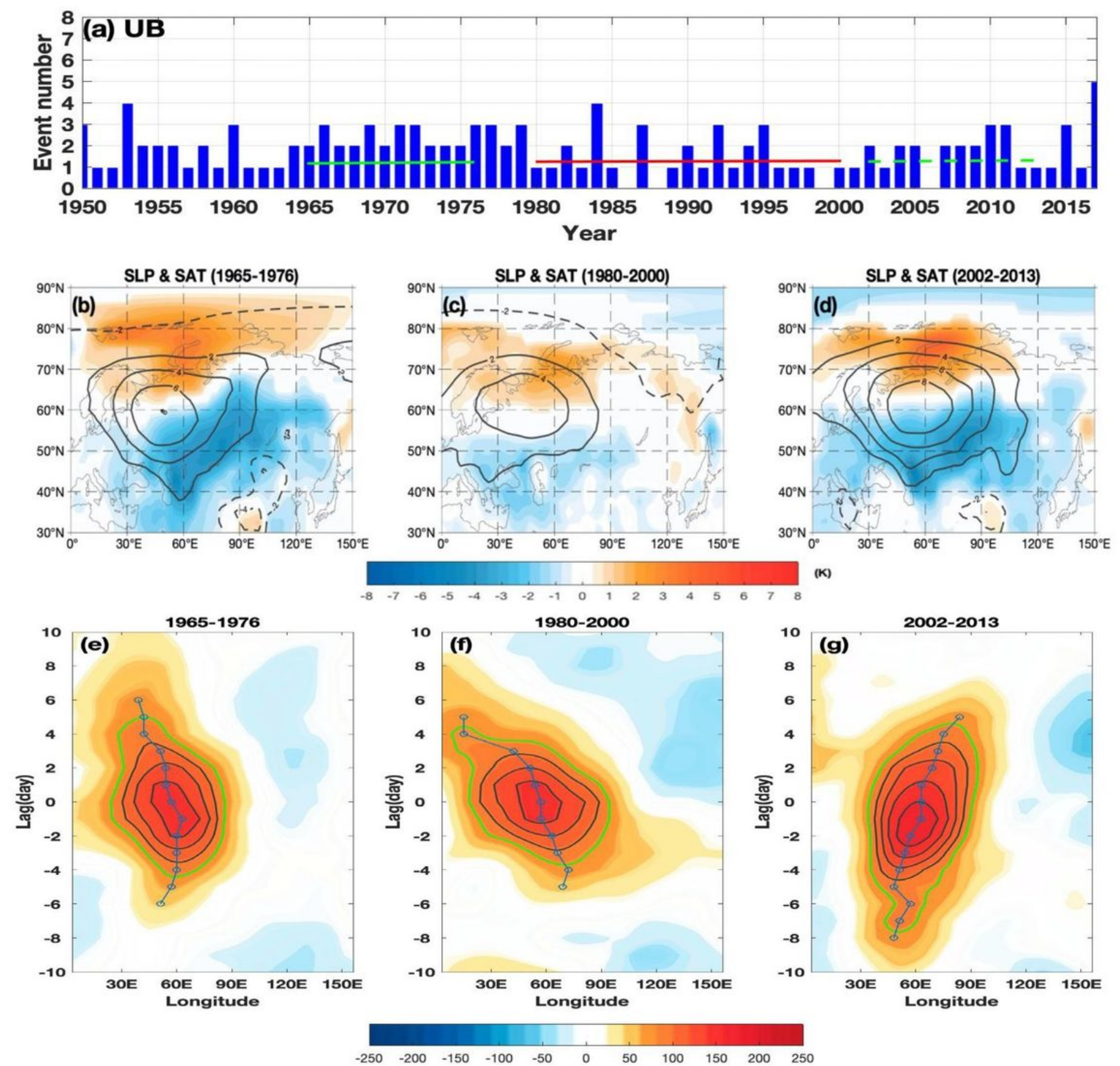

Figure 2

(a) Time series of the number of winter Ural blocking (UB) events (a total of 126 cases) during 1950-2017 with three sub-periods: 1965-1976 (29 cases, blue line), 1980-2000 (30 cases; red line) and 2002-2013 (21 cases; dashed green line). (b, c, d) Time-mean composite daily SLP (contours, $\mathrm{Cl}=2 \mathrm{hPa}$ ) and SAT (color 
shading, in K) anomalies averaged from lag -10 to 10 days (lag 0 denotes the peak day of blocking) for (b) 29 UB events during 1965-1976, (c) 30 UB events during 1980-2000 and (d) 21 UB events during 20022013. (e, f, g) Time-longitude evolution of the composite daily $\mathrm{Z} 500$ anomalies (unit: $\mathrm{gpm}$ and $\mathrm{Cl}=20$ $\mathrm{gpm}$ ) averaged over 50o-70oN of the UB events during (e) 1965-1976, (f) 1980-2000 and (g) 2002-2013. In (e-g), the $80 \mathrm{gpm}$ contour is marked by the green line and the thick blue line denotes the zonal location of the maximum daily Z500 anomaly whose temporal variation represents the movement speed. The color shading represents the region above the $95 \%$ confidence level based on a two-sided Student t-test.
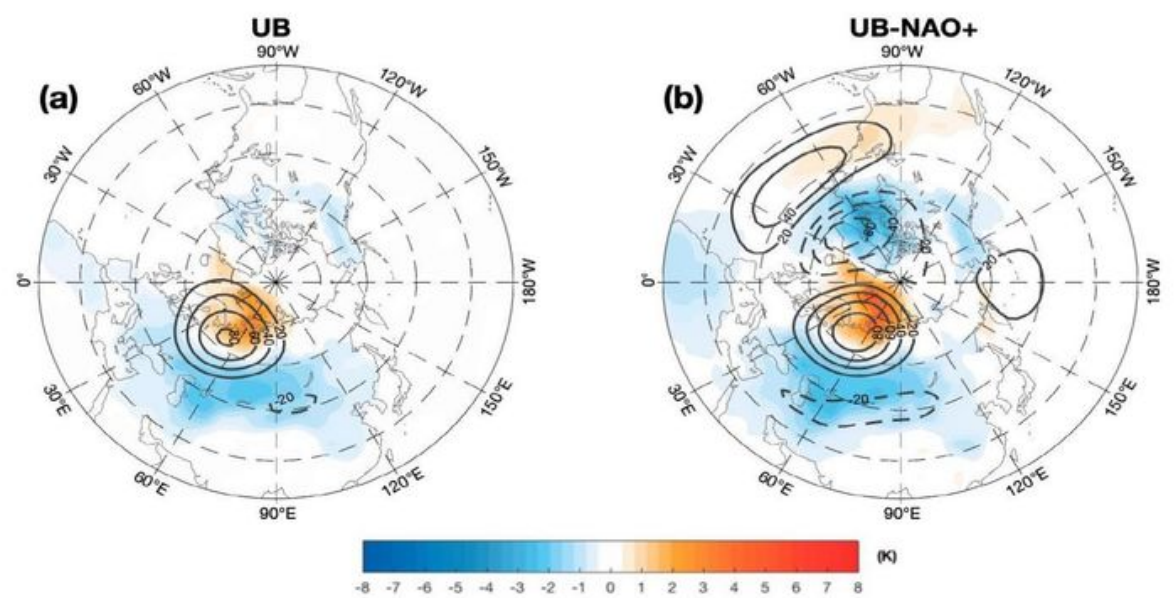

1965-1976 minus 2002-2013

1965-1976 minus 2002-2013

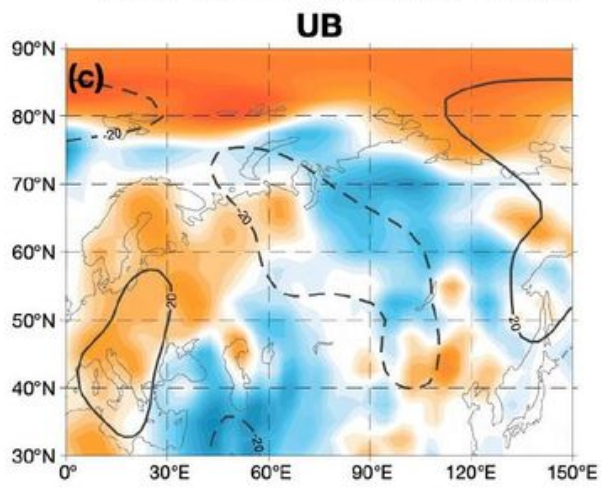

UB-NAO ${ }^{+}$
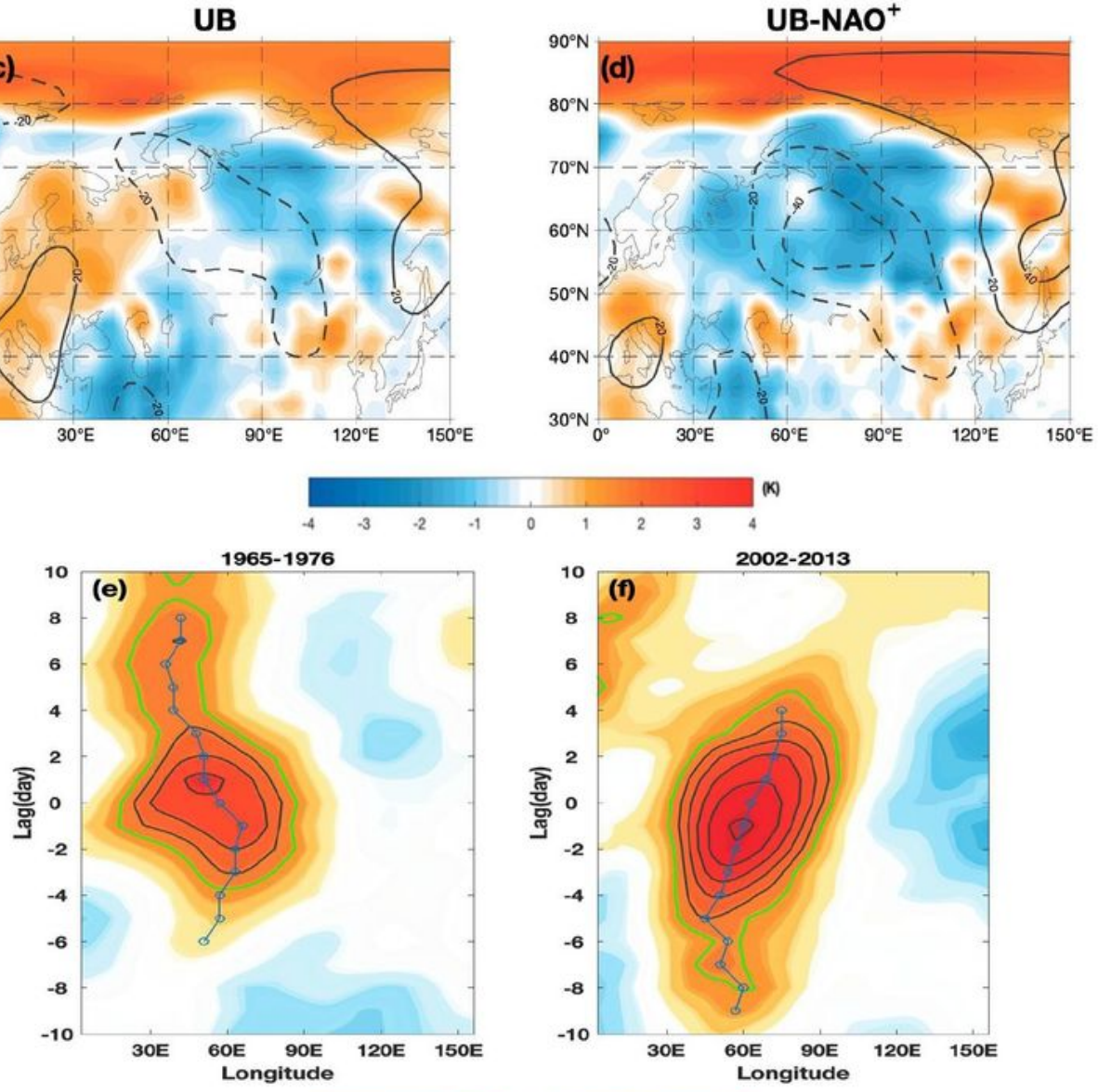

$\begin{array}{lllllllllll}-250 & -200 & -150 & -100 & -50 & 0 & 50 & 100 & 150 & 200 & 250\end{array}$ 


\section{Figure 3}

Time-mean composite daily 500-hPa geopotential height (Z500) (contours, $\mathrm{Cl}=20 \mathrm{gpm}$ ) and SAT (color shading, unit: K) anomalies averaged from lag -10 to 10 days (lag 0 denotes the peak day of blocking) for (a) UB and (b) UB-NAO+ events during 1950-2017. (c, d) 1965-1976 minus 2002-2013 differences of timemean Z500 and SAT anomalies for (c) UB and (d) UB-NAO+ events, where the color shading represents the region above the $95 \%$ confidence level based on a two-sided Student t-test. (e, f) Time-longitude evolution of composite daily $\mathrm{Z} 500$ anomalies (unit: gpm and $\mathrm{Cl}=20 \mathrm{gpm}$ ) averaged over $50 \mathrm{o}-70 \mathrm{oN}$ of UBNAO+ events during (e) 1965-1976 and (f) 2002-2013. The $80 \mathrm{gpm}$ contour is marked by the green line and the thick blue line with dot denotes the zonal location of the maximum daily Z500 anomaly and its temporal variation represents the movement speed.

(a)

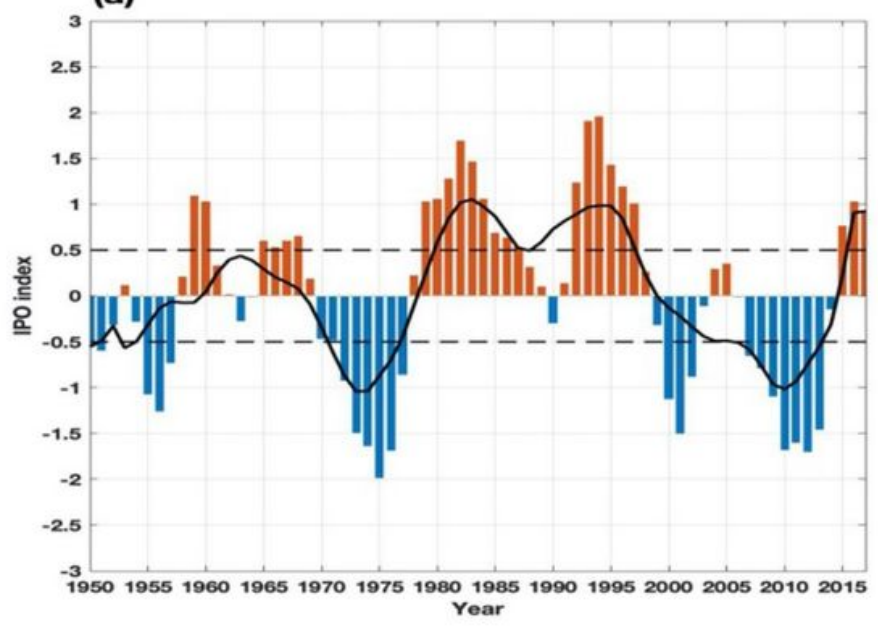

(c) SST (1965-1976)
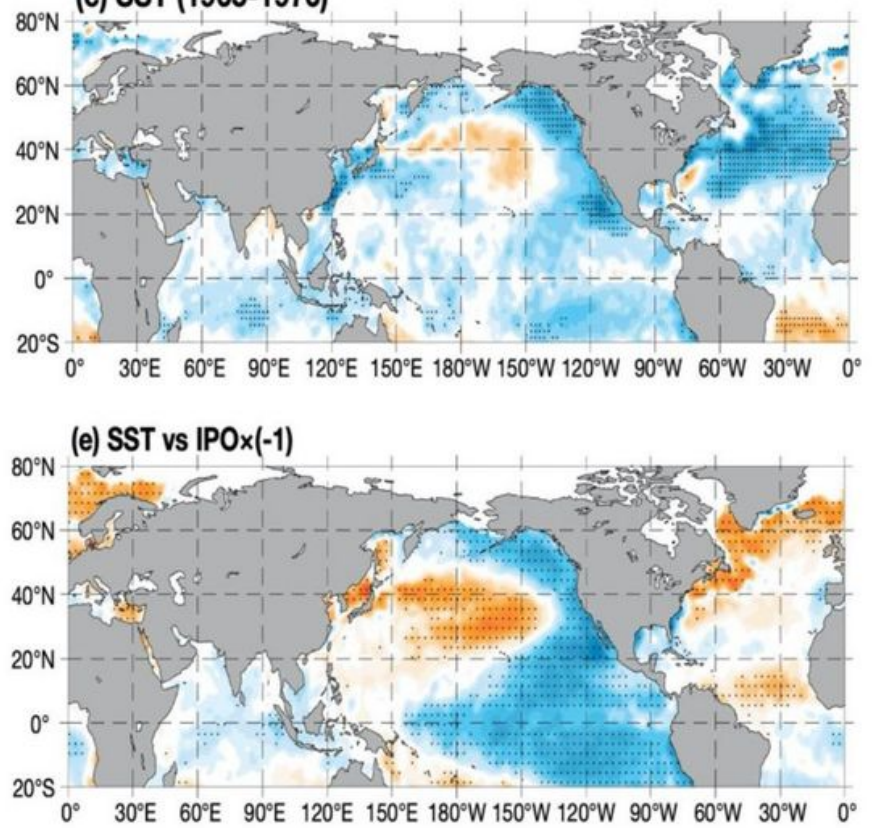

(b)

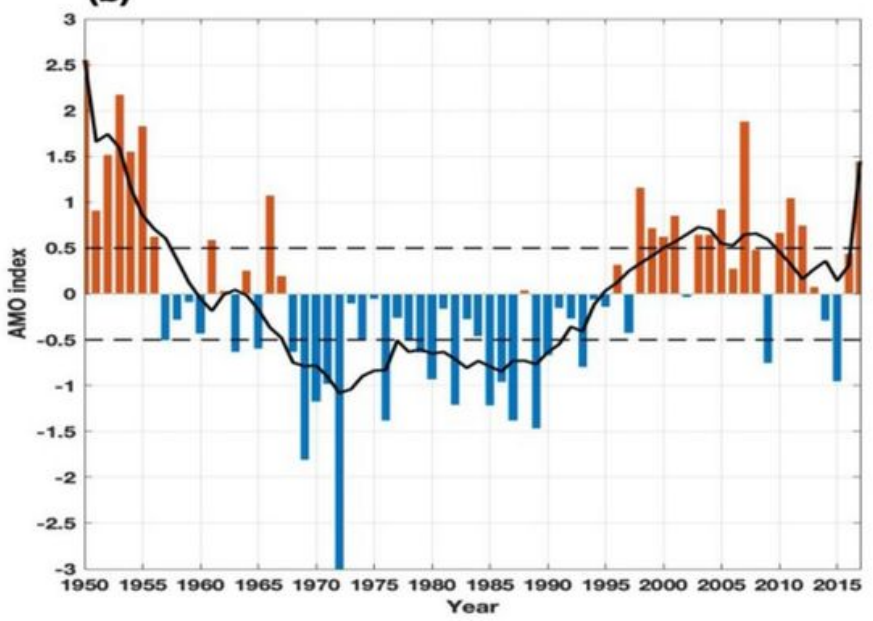

(d) SST (2002-2013)
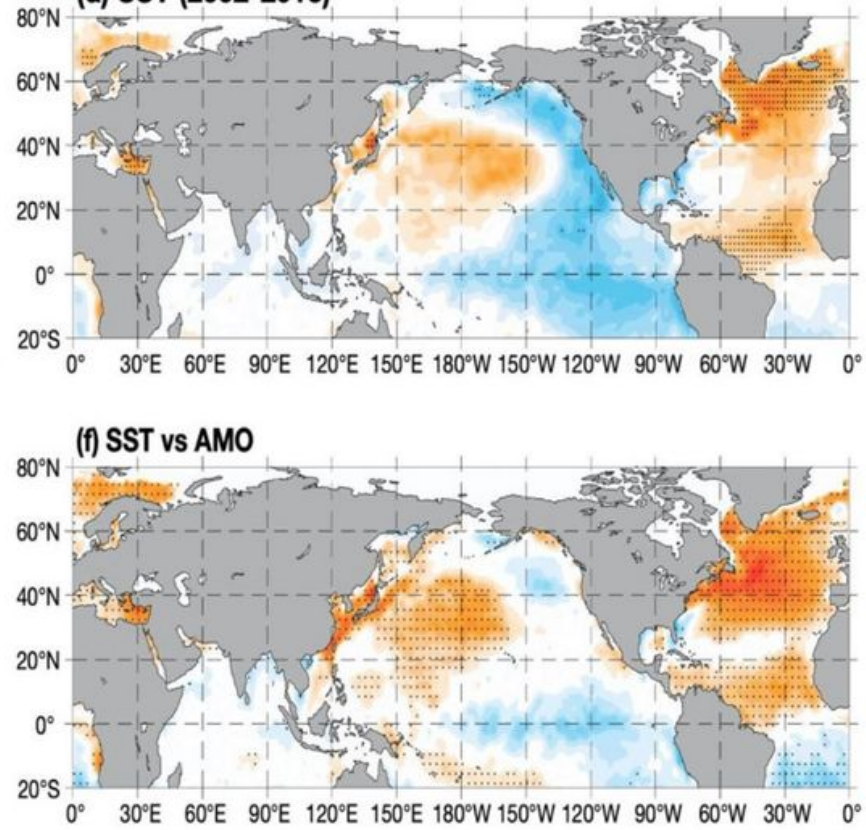

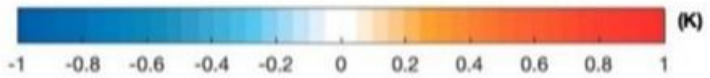




\section{Figure 4}

(a, b) Time series of normalized DJF-mean (a) Interdecadal Pacific Oscillation (IPO) and (b) Atlantic Multidecadal Oscillation (AMO) indices during 1950-2017, where the black solid line represents a 9-year moving average. (c, d) Time-mean winter SST anomalies during (c) 1965-1976 and (d) 2002-2013. (e, f) regressed DJF-mean SST (color shading, in K per unit index) against the normalized (a) DJF-mean IPO index (multiplied by -1.0) and (b) AMO index time series with a 9-year moving average. In panels e-f, the dot in the color shading region represents the region above the $95 \%$ confidence level based on a twosided Student t-test. Note: The designations employed and the presentation of the material on this map do not imply the expression of any opinion whatsoever on the part of Research Square concerning the legal status of any country, territory, city or area or of its authorities, or concerning the delimitation of its frontiers or boundaries. This map has been provided by the authors. 

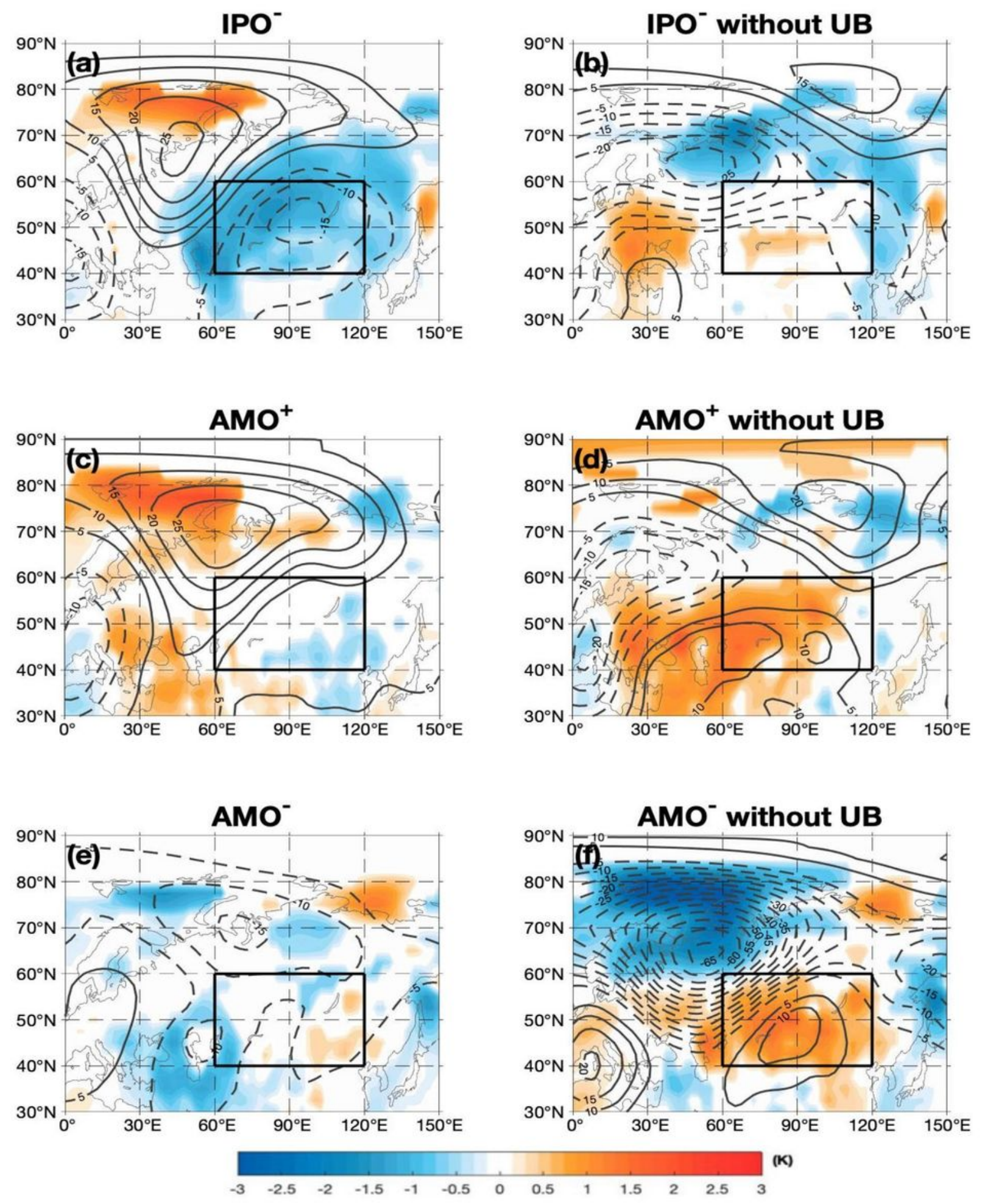

Figure 5

Composite DJF-mean Z500 (contours, unit: gpm) and SAT (color shading) anomalies in (a, b) IPO-, (c, d) AMO+ and (e, f) AMO- winters during 1950-2017 based on the 0.5 STD threshold value definition of 9-year smoothed IPO and AMO indices for days $(a, c, e)$ with and (b, d, f) without UB events (the case without UB represents that blocking days from lag -10 to 10 are removed for each UB event in winter). The composite field with UB events during IPO- (AMO- or AMO+) is referred to as the IPO- (AMO- or AMO+) case, whereas 
the composite field without UB events (blocking days from lag -10 to 10 days are removed) during IPO$(\mathrm{AMO}-$ or $\mathrm{AMO}+)$ is referred to as the IPO- $(\mathrm{AMO}-$ or $\mathrm{AMO}+)$ without UB case. Color shading represents the areas being significant at the $95 \%$ level based on a two-sided Student t-test. Black box represents Siberia
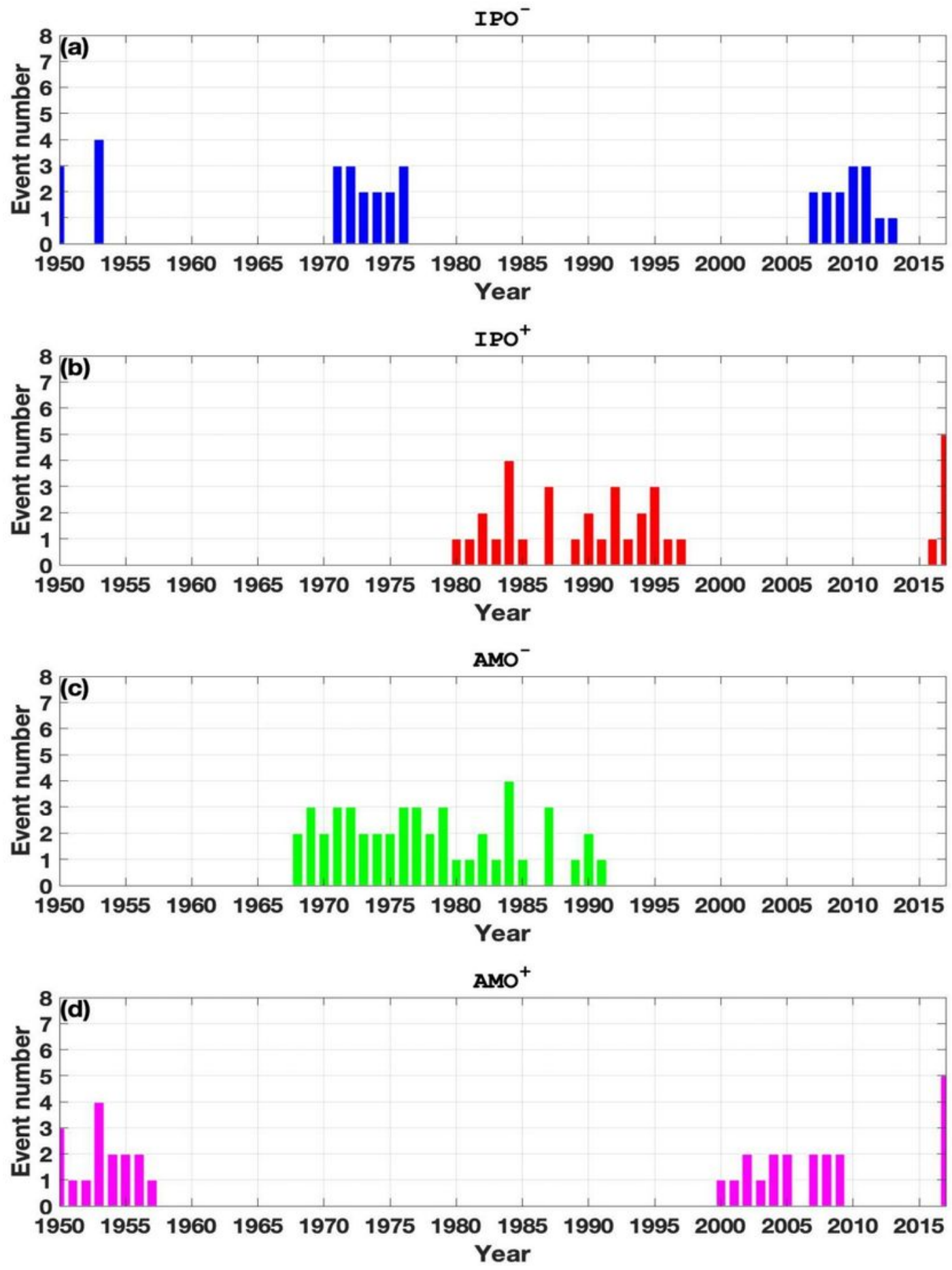

Figure 6

(a, b, c, d) Time series of winter UB events during (a) IPO-, (b) IPO+, (c) AMO- and (d) AMO+ based on the 0.5 STD definitions of the normalized 9-year moving averaged IPO and AMO indices during 1950-2017. 

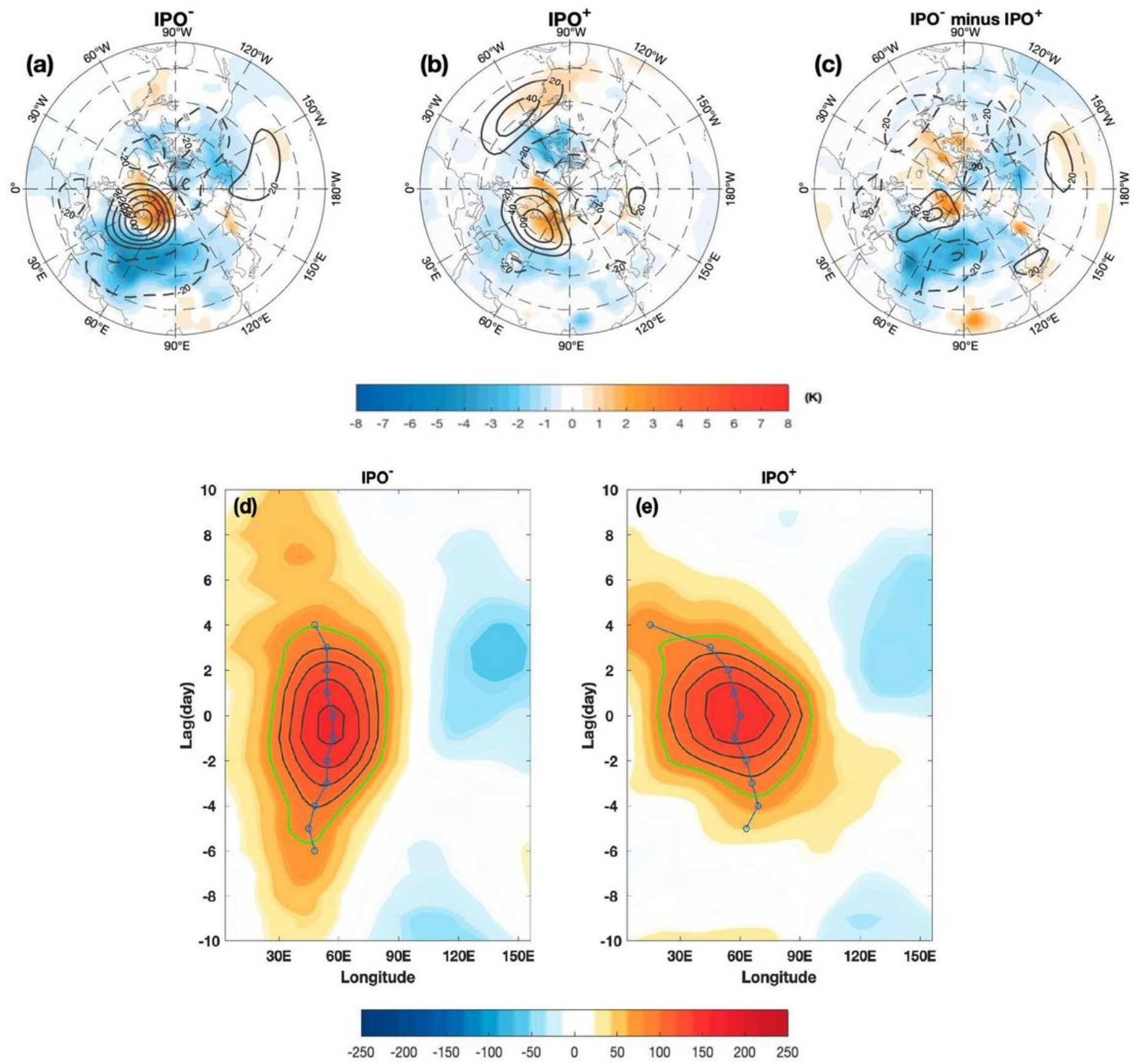

\section{Figure 7}

Time-mean composite daily $\mathrm{Z} 500$ (contour; $\mathrm{Cl}=20 \mathrm{gpm}$ ) and SAT (color shading) anomalies averaged from lag -10 to 10 days (lag 0 denotes the peak day of blocking) of 36 UB events during (a) IPO- (16 cases), (b) 34 UB events during IPO+ (19 cases) and (c) IPO- minus IPO+ difference based on the 0.5 STD definition of the 9-year moving averaged IPO index. (d, e) time-longitude evolution of composite daily $\mathrm{Z} 500$ anomalies (contours; the green line represents $80 \mathrm{gpm}$ and $\mathrm{Cl}=20 \mathrm{gpm}$ ) averaged over the latitudes $50 \mathrm{o}-70 \mathrm{oN}$ of UB events during (d) IPO- and (e) IPO+. In panels a-b, the color shading represents the region above the $95 \%$ confidence level based on a two-sided Student t-test. In panels c-d, the thick blue line 
denotes the zonal location of the maximum daily Z500 anomaly and its temporal variation represents the movement speed.
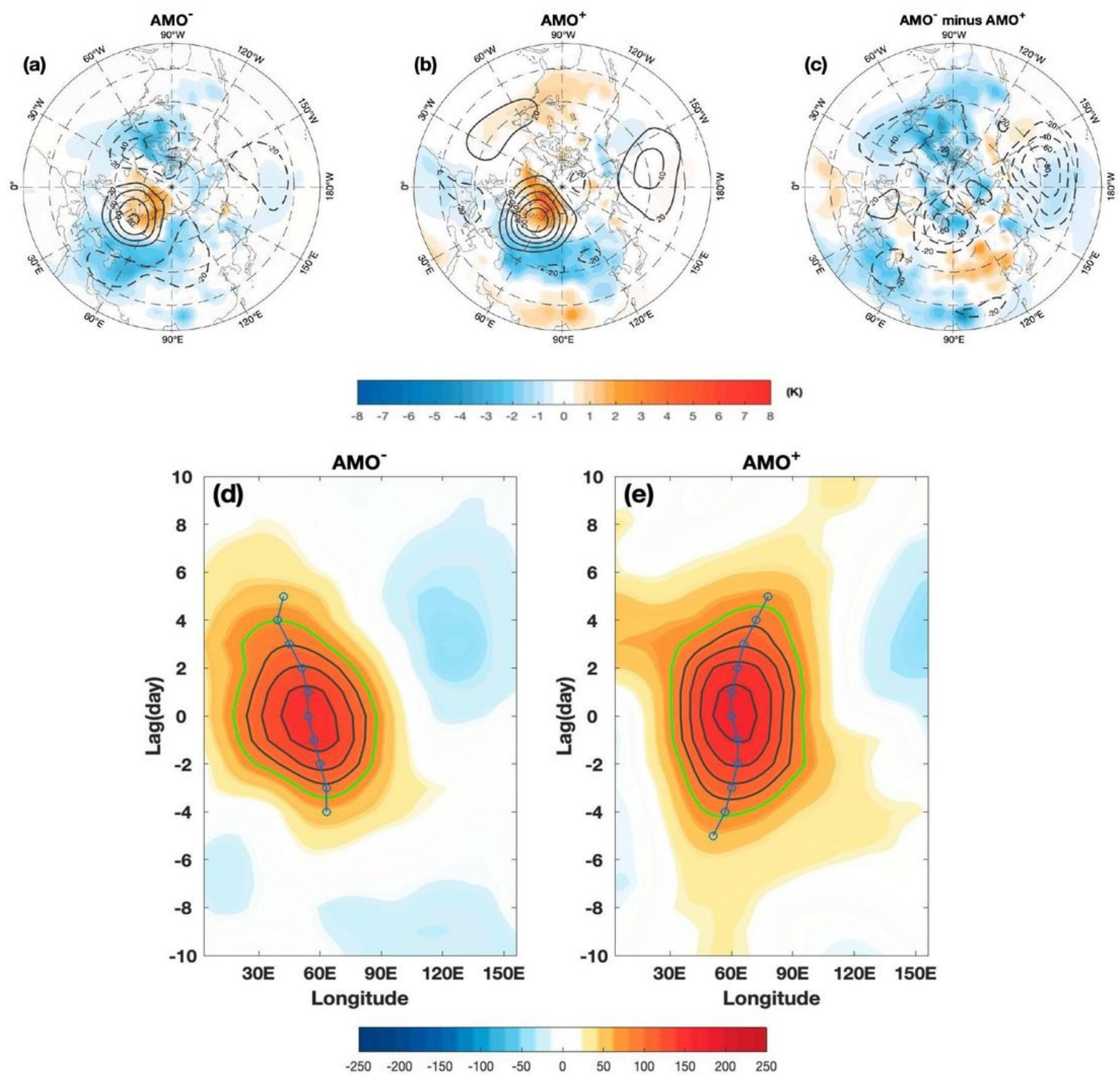

\section{Figure 8}

Time-mean composite daily $\mathrm{Z} 500$ (contours, $\mathrm{Cl}=20 \mathrm{gpm}$ ) and SAT (color shading, in $\mathrm{K}$ ) anomalies averaged from lag -10 to 10 days (lag 0 denotes the peak day of blocking) for the (a) 43 UB events during AMO- (22 cases), (b) $33 \mathrm{UB}$ events during AMO+ (18 cases) and (c) AMO- minus AMO+ difference based on the 0.5 STD definition of the 9-year moving averaged AMO index from 1950-2017. (d, e) Timelongitude evolution of composite daily Z500 anomalies (unit: gpm, the green line represents the $80 \mathrm{gpm}$ 
contour and $\mathrm{Cl}=20 \mathrm{gpm}$ ) averaged over the latitudes $50 \mathrm{o}-70 \mathrm{oN}$ of the UB events during (d) AMO- and (e) AMO+. In panels $a-b$, the color shading represents the region with SAT anomalies above the $95 \%$ confidence level based on a two-sided Student t-test. In panels $d-e$, the thick blue line denotes the zonal location of the maximum daily Z500 anomaly and its temporal variation represents the movement speed.
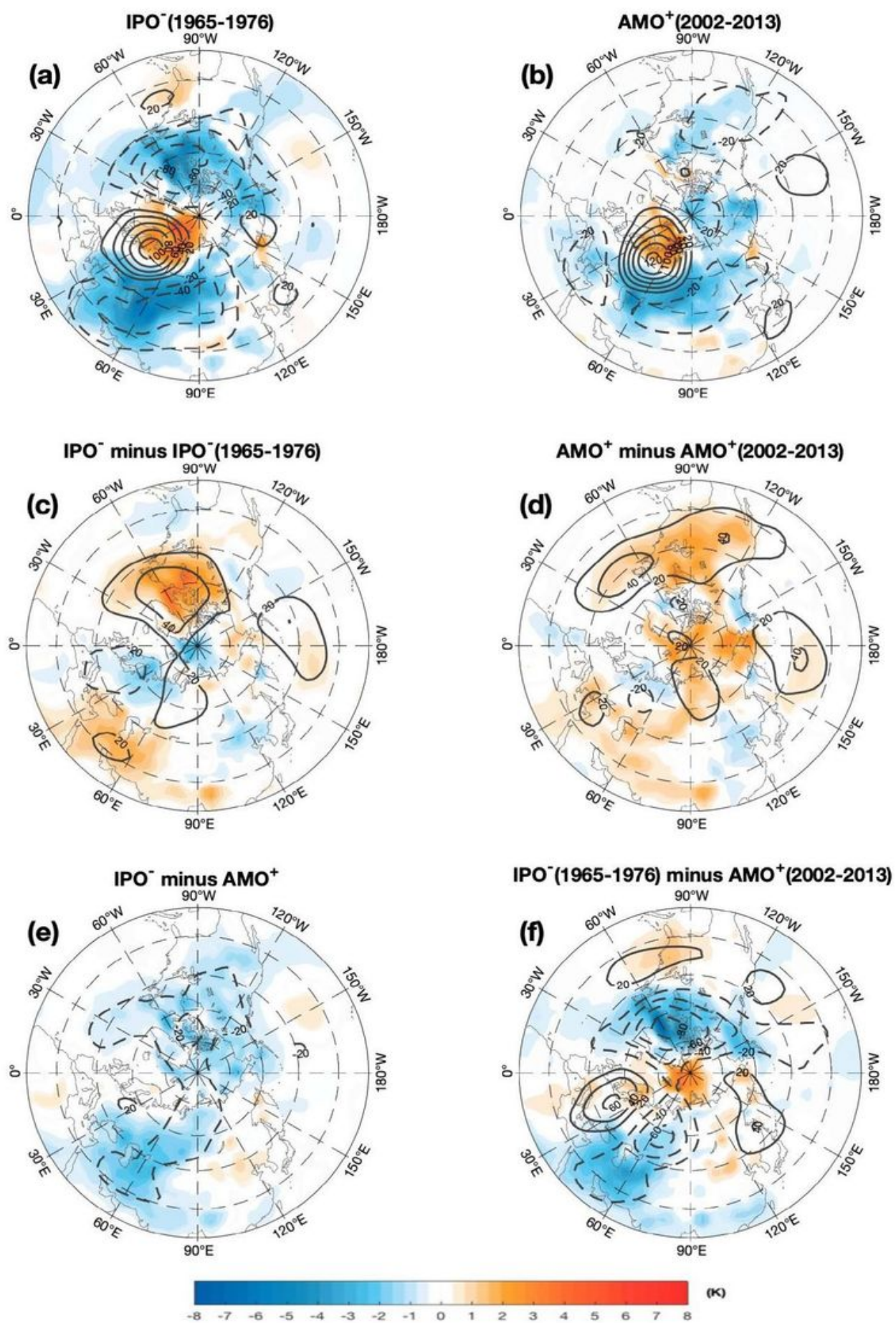

Figure 9 
Time-mean composite daily $\mathrm{Z} 500$ (contours, $\mathrm{Cl}=20 \mathrm{gpm}$ ) and SAT (color shading, in $\mathrm{K}$ ) anomalies averaged from lag -10 to 10 days (lag 0 denotes the peak day of blocking) of UB events for IPO- during (a) 1965-1976 (20 UB events) and (b) AMO+ during 2002-2013 (21 UB events) as well as (c) IPO- during 1950-2017 minus IPO- (1965-1976), (d) AMO+ during 1950-2017 minus AMO+ (2002-2013), (e) IPOminus AMO+ during 1950-2017 and (f) IPO- (1965-1976) minus AMO+ (2002-2013) differences based on 9-year smoothed IPO and AMO indices. The color shading represents the region above the $95 \%$ confidence level based on a two-sided Student t-test.
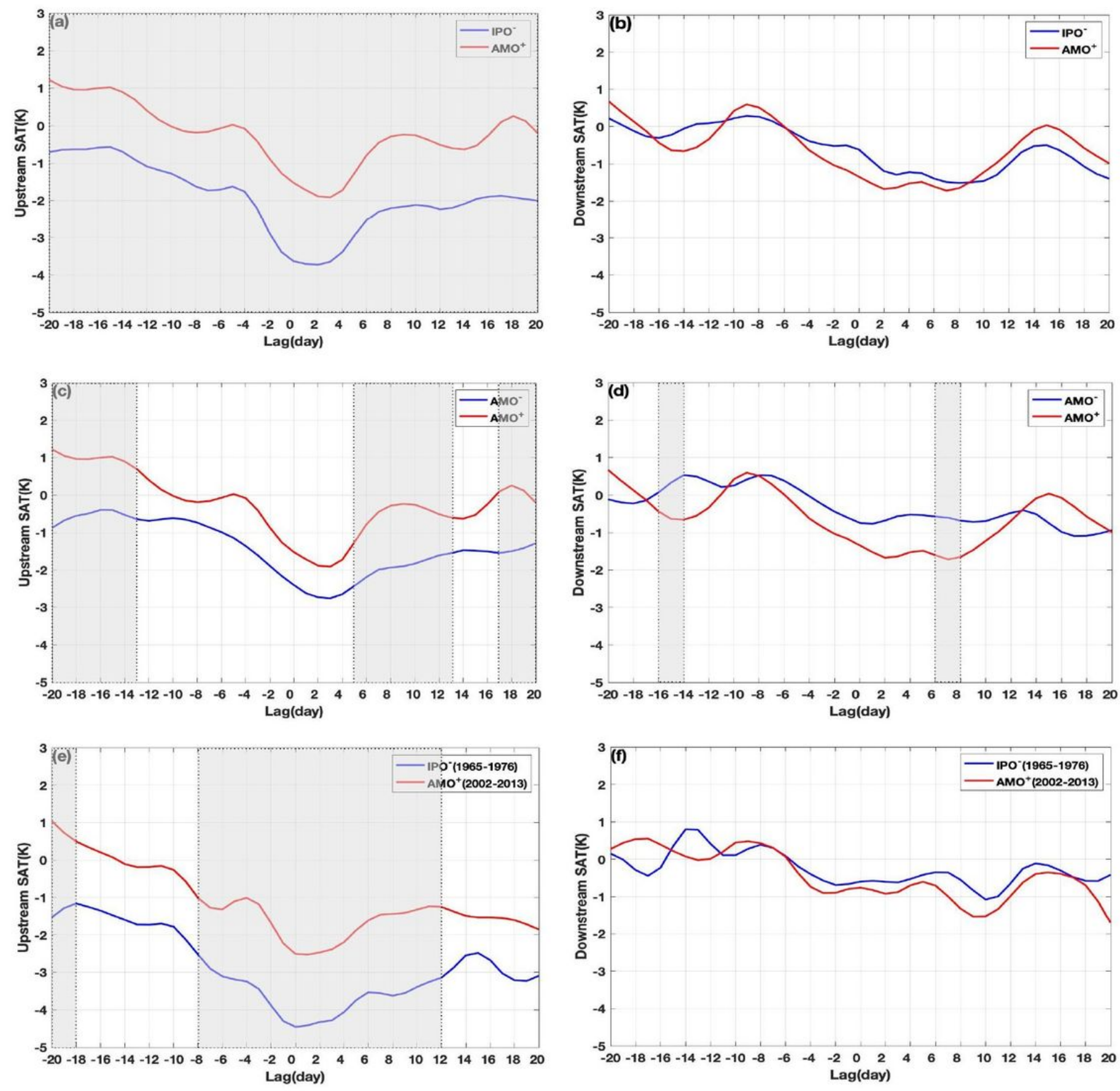

Figure 10 
Time evolution of composite daily SAT anomalies averaged over (a, c, e) upstream (30o-50oN, 30o-70oE) and $(b, d, f)$ downstream $(30 \mathrm{o}-50 \mathrm{oN}, 90 \mathrm{o}-130 \mathrm{oE})$ regions, referred to as upstream and downstream SAT anomalies, during the UB life cycle from lag -20 to 20 days (lag 0 denotes the peak day) for UB events during IPO- (blue line), AMO- (blue line) and AMO+ (red line) during (a, b, c, d)1950-2018 and (e, f) 19651976 and 2002-2013. The gray shading represents the difference of two curves being significant at the $95 \%$ confidence level for a Monte-Carlo test based on a 5000 times simulation.
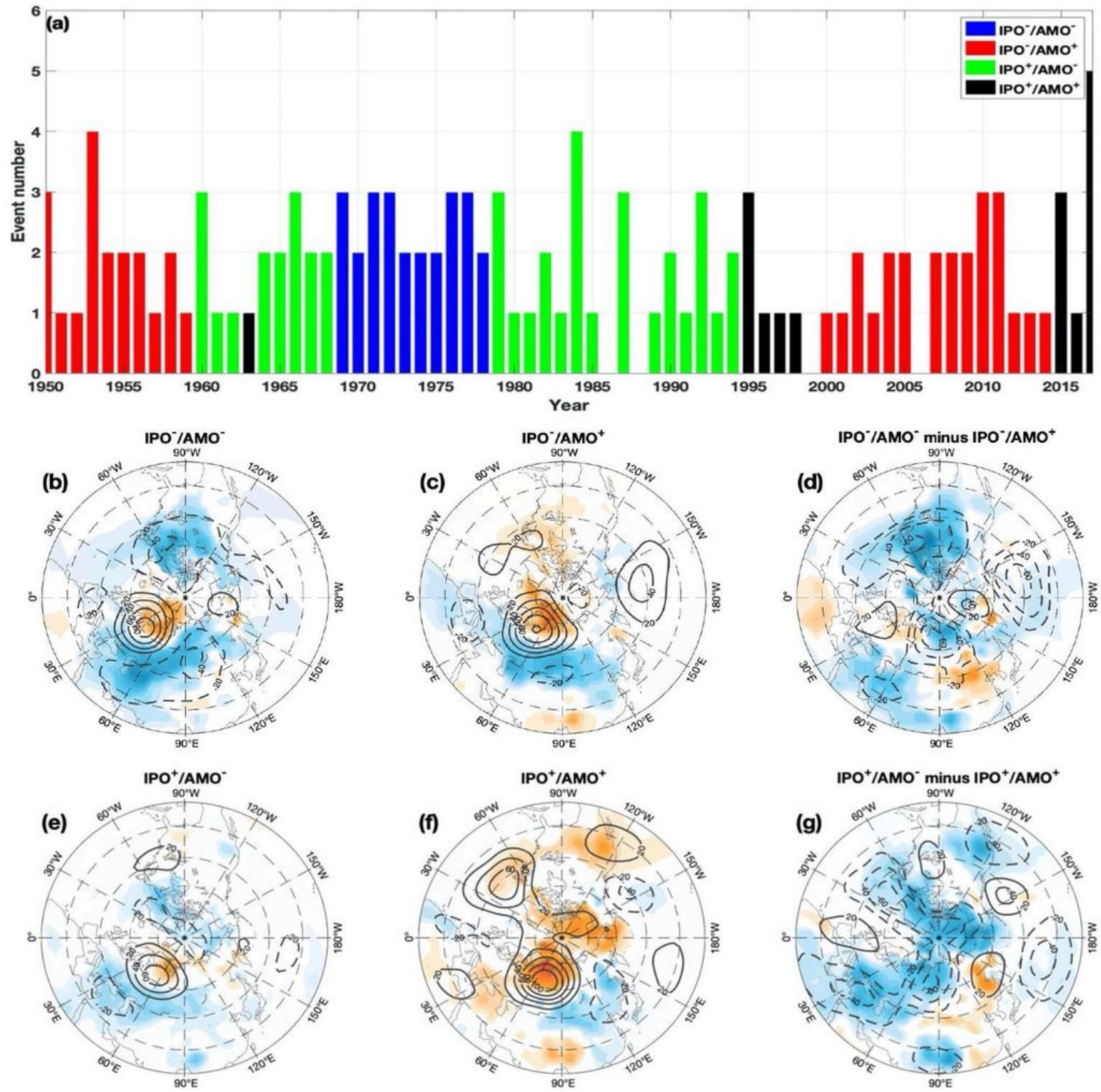

(K)

Figure 11 
(a) Time series of winter UB events in winter for IPO- /AMO- (10 cases, blue), IPO-/AMO+ (24 cases, red), IPO+/AMO- (22 cases, green), and (black) IPO+/AMO+ (8 cases, black) combinations based on 9-year smoothed IPO and AMO indices. (b, c, d, e) Time-mean Z500 (contour, $\mathrm{Cl}=20 \mathrm{gpm}$ ) and SAT (color shading) anomalies averaged from lag -10 to 10 days (lag 0 denotes the peak day of blocking) of 25, 43, 42 and 16 UB events during (b) IPO-/AMO-, (c) IPO-/AMO+, (d) IPO+/AMO-, and (e) IPO+/AMO+ combinations. In panels b-e, the color shading represents the region above the $95 \%$ confidence level based on a two-sided Student t-test.
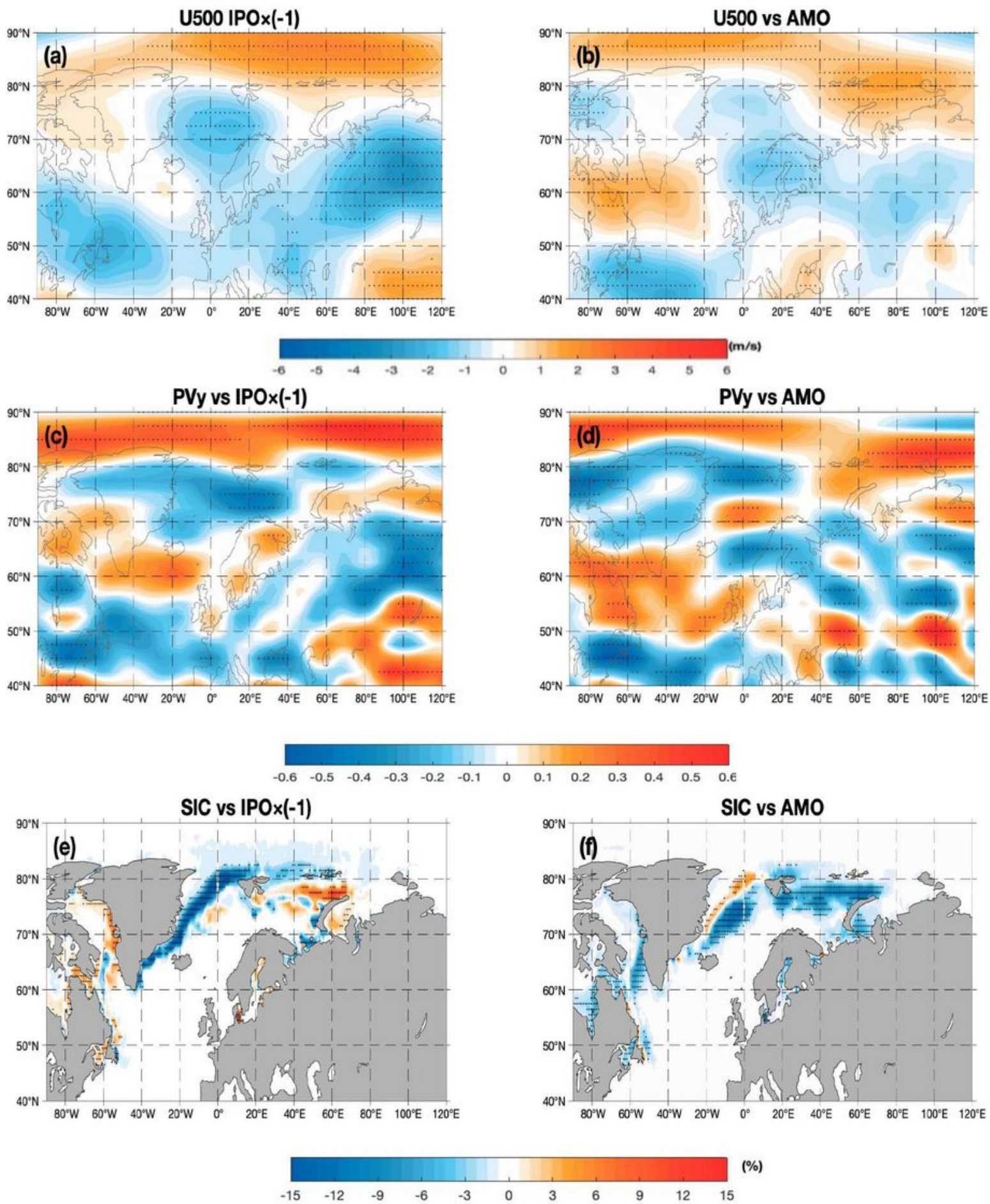
Figure 12

DJF-mean ( $a, b)$ U500, (c, d) non-dimensional PVy for UB events removed and (e, f) SIC anomalies regressed onto the time series of normalized DJF-mean ( $a, c, e)$ IPO index (multiplied by -1.0) and (b, d, f) AMO index with a 9-year smoothing. The dot represents the region above the $95 \%$ confidence level for a two-sided Student t-test.

\section{Supplementary Files}

This is a list of supplementary files associated with this preprint. Click to download.

- Supplementaryfile416.pdf 